\title{
On the Use of Multifactor Models to Evaluate Mutual Fund Performance
}

\author{
Joop Huij and Marno Verbeek
}

We show that multifactor performance estimates for mutual funds suffer from systematic biases, and argue that these biases are a result of miscalculating the factor premiums. Because the factor proxies are based on hypothetical stock portfolios and do not incorporate transaction costs, trade impact, and trading restrictions, the factor premiums are either over- or underestimated. We argue that factor proxies based on mutual fund returns rather than stock returns provide better benchmarks to evaluate professional money managers.

We thank Vikas Agarwal, Klaas Baks, Gurdip Bakshi, Nick Bollen, Mathijs van Dijk, Robert Kosowski, Federico Nardari, Frans de Roon, seminar participants at the University of Mannheim, the 2006 European Finance Association meeting in Zurich, and the 2007 Financial Management Association meeting in Orlando, and an anonymous referee for helpful comments and suggestions. Also, we gratefully acknowledge research support from the Erasmus Research Institute of Management, Netherlands Organization for Scientific Research, and Trustfund Erasmus University Rotterdam. We thank Sandra Sizer for excellent editorial assistance.

*Huij and Verbeek are at RSM Erasmus University, Rotterdam. Huij is also at Robeco Asset Management. Verbeek is also at Netspar. Corresponding author is Huij. Email addresses are jhuij@rsm.nl and mverbeek@rsm.nl. The usual disclaimer applies. 
In this paper we evaluate the cross-sectional power of multifactor models to explain mutual fund returns, and we examine the consequences of using these models to evaluate mutual fund performance. First, we identify the extent to which professional money managers are able to capture the value, size, and momentum premiums implied by the hypothetical hedge portfolios that underlie these factors. Second, we analyze extent to which the use of these factor proxies systematically biases the performance estimates of mutual funds. Our main concern is that factor proxies in the standard multifactor approaches are based on hypothetical stock portfolios that do not incorporate transaction costs, trade impact, and trading restrictions. Therefore, the factor premiums are likely to be over- or underestimated, so the resulting performance estimates for funds with significant exposure to these factors may be biased.

For example, consider two zero-alpha fund managers (i.e., managers with no skill). The first manager runs a fund with unit exposure to the market factor, and the second manager a fund with unit exposure to the value factor. Suppose that the market premium is overestimated by $0.3 \%$. Alpha estimates for the first fund asymptotically converge to minus $0.3 \%$. Now, suppose that there is a positive value premium, but that this premium is overestimated by $3 \%$. Doing so will cause alpha estimates for the second fund to converge to minus 3\%. Based on the alpha estimates for both funds, we might incorrectly infer that the manager of the first fund is more skilled. In fact, we might even infer, again incorrectly, that some funds systematically outperform the passive factors. To illustrate this point, consider a third zero-alpha manager, but suppose that this manager follows a growth strategy and has an exposure of minus one to the value factor. Now, because we use a value proxy that projects a larger return differential between growth and value funds than there actually is, the fund's alpha estimate converges to plus $3 \%$. Thus, miscalculation of the factor premiums might lead not only to false inferences about relative fund performance, but also about market efficiency as a whole.

Miscalculation of the factor premiums is a general concern, i.e., even if fund returns were fully described by a single-factor model, overestimation of the 
premium on this factor will cause performance estimates to be biased.

Nevertheless, we argue that there are good reasons to believe that the resulting biases are more important for multifactor approaches. Because the transaction costs of tracking the market index are as low as 30 basis points per year, it is unlikely that the resulting biases in CAPM performance estimates are economically significant. However, the costs that are involved with mimicking the hypothetical hedge portfolios used with multifactor approaches are many times larger.

Another reason to believe that the factor premiums earned by fund managers are different from the ones implied by the factor proxies is that mutual fund managers may have a restricted universe of stocks that are accessible to them, or they may be faced with other trading restrictions. For example, large funds might not even attempt to buy stocks below a certain level of liquidity or a certain market capitalization.

In this paper we ask how far fund managers are able to exploit the anomalies reported in other studies. Do the proxies that are used with multifactor approaches systematically over- or underestimate the premiums fund managers actually earn by following the anomalous styles? And if so, how does this bias affect the performance estimates of mutual funds based on multifactor models. By answering these questions and by considering the investment performance of open-end mutual funds that try to exploit them, we can determine the economic significance of the small-cap, value, and momentum anomalies. Moreover, we can determine the impact of a particular form of benchmark misspecification on mutual fund performance estimates. ${ }^{1}$ To answer these questions we use the mutual funds database of the Center for Research in Security Prices (CRSP) and analyze monthly mutual fund returns over the period 1963-2003.

We find a value premium and a momentum effect in the cross-section of fund returns, but do not find evidence of a small firm-effect. However, although

\footnotetext{
${ }^{1}$ Other studies that investigate the implications of benchmark misspecification for performance evaluation are Roll (1978), Lehman and Modest (1987), Grinblatt and Titman (1994) and Coles et al. (2006).
} 
funds with a value-oriented style earn returns higher than predicted by the singlefactor CAPM, their premium is significantly smaller than projected by the Fama and French (1993) value proxy HML that most multifactor approaches use. Similarly, funds that hold stocks that did well over the past year will earn returns that are higher than predicted by the CAPM, but the return differential between past winners and losers is much larger than predicted by the Carhart (1997) momentum proxy WML.

Our second set of results concerns the implications of these findings for the evaluation of mutual fund performance. Because of the miscalculation of the premiums of the hypothetical hedge portfolios, alphas resulting from the Fama and French $(1993,1995,1996)$ three-factor model (henceforth, Fama-French 3FM) and the Carhart (1997) four-factor model (henceforth, Carhart 4FM) for value funds are systematically biased downwards, and those for growth funds are biased upwards. Further, the Carhart 4FM underestimates the performance of past loser funds and overestimates that of winner funds. We demonstrate that these results cannot be explained by time-varying market betas, alternative cutoff points to compute factor premiums, and differences in the funds' expense ratios. Our results indicate that factor proxies based on mutual fund returns rather than stock returns provide better benchmarks to evaluate professional money managers.

The paper is organized as follows: Section I describes the data and construction of style portfolios of mutual funds. Section II tests the cross-sectional explanatory power of the factor models. Section III examines the robustness of our results. Section IV presents the results using factor proxies based on fund returns. Section V concludes.

\section{Data Sources and Construction of Style Portfolios}

We obtain data on returns of mutual funds from the 2003 CRSP Mutual Fund Survivor-Bias-Free Database. This database covers monthly total returns of more than 21,400 open-end mutual funds over the period 1962-2003. Of these funds, about 7,000 are dead. We follow a procedure similar to Pastor and 
Stambaugh (2002a,b) and use the CRSP information on fund classifications, expenses, and load data to construct a sample of U.S. equity funds. We exclude funds that have no classification, expense, or load data in the annual summary at the end of each previous year. We also examine fund classifications at the end of each previous year, and exclude flexible funds, bond funds, mortgage-backed funds, multimanager funds, money market funds, balanced funds, funds that invest in precious metals, and international funds. From the remaining funds, we select funds that are classified as small-cap growth, growth, growth and income, income, or sector funds. These are the same types of funds that are included in the analyses of Carhart (1997) and Bollen and Busse (2005). We drop funds with less than 12 consecutive returns over the entire sample period. In total, our sample covers 7,852 funds over the period 1963-2003. Since CRSP basically includes all funds that existed during this period, our data are free of the survivorship bias documented by Brown et al. (1992) and Brown and Goetzmann (1995). Because we require that to be included in our sample, funds must have an annual summary available at the end of each previous year, our first return observation is over January 1963. All returns are net of operating expenses.

We build quantile portfolios of funds based on the funds' styles. As explained by Fama and MacBeth (1973), using such an approach reduces the "errors-in-variables" problem in the estimated factor exposures. We construct the style portfolios in the following way. Each month, we sort all available funds into ten, 20 , or 30 mutually exclusive portfolios based on one of the following characteristics of their stock holdings: market beta, size beta, value beta, and past return. Funds' market betas are obtained by running the CAPM regressions for all available funds using ordinary least squares (OLS) with a rolling window over the preceding 36 months:

$$
r_{i, t}=\alpha_{i}+\beta_{i} R M R F_{t}+\varepsilon_{i, t}
$$


where $r_{i, t}$ is the excess return of fund $\mathrm{i}$ in month $\mathrm{t}, R M R F_{t}$ is the excess return on the market portfolio in month $\mathrm{t}, \alpha_{i}$ is Jensen's (1968) alpha, $\beta_{i}$ is the market beta of fund $\mathrm{i}$, and $\varepsilon_{i, t}$ is the residual return of fund $\mathrm{i}$ in month $\mathrm{t}$.

We obtain the funds' size and value betas by estimating the Fama-French 3FM using OLS with a rolling window over the preceding 36 months:

$$
r_{i, t}=\alpha_{i}+\beta_{1, i} R M R F_{t}+\beta_{2, i} S M B_{t}+\beta_{2, i} H M L_{t}+\varepsilon_{i, t}
$$

where $S M B_{t}$ and $H M L_{t}$ are the excess returns on the factor-mimicking portfolios for market equity (small minus big, SMB) and book-to-market-equity (high minus low, $\mathrm{HML}$ ) in month t. We obtain the benchmark returns on RMRF, SMB and $H M L$ from the data library of French (2004). As a proxy for the risk-free rate, we use the one-month Treasury bill rate from Ibbotson and Associates. Consistent with many other studies, we base portfolios on past return on the funds' average return over the past 12 months.

With sorts on market, size, and value betas, the top quantile contains the funds with the highest estimated exposure to the relevant factor (e.g., $\beta_{1, i}, \beta_{2, i}$, and $\left.\beta_{3, i}\right)$. For example, if we sort funds into deciles based on their size betas, then the top decile contains the $10 \%$ of funds with the highest exposure to the size factor, and the bottom decile contains the $10 \%$ of funds with the lowest exposure to the size factor. If we base the sorts on the funds' value betas, then the top decile contains the $10 \%$ of funds with the highest exposure to the value factor, and the bottom decile the $10 \%$ of funds with the lowest exposure to the value factor. For portfolios on past returns, the top quantile contains the funds with the highest average return over the past year.

After sorting the funds into quantile portfolios, we calculate the equally weighted returns over the subsequent (out-of-sample) month for all portfolios. If a fund disappears from our sample after ranking, we readjust the portfolio weights. We use the first three years of our data set (January 1963 to December 1965) to 
initialize the style portfolios. Thus, the style portfolio returns cover the period January 1966 to December 2003.

\section{Empirical Results}

In this section, we ask how far mutual fund managers are able to exploit the anomalies reported in other studies, and whether the proxies that are used with multifactor approaches systematically miscalculate the premiums fund managers actually earn by following the anomalous styles.

\section{A. The value and momentum anomalies}

The first question we address is whether a linear function of their market betas fully describes the returns of the mutual fund style portfolios. Our first series of results comes from scatter plots of the style portfolios' expected returns against their market betas. For all style portfolios, we compute the average excess returns over the entire sample period, and then plot these values on the portfolios' post-ranking market betas that we estimate by using the CAPM in Equation (1). These market beta estimates are also based on the entire sample period. The resulting scatter plots are presented in Figure 1.

\section{<INSERT FIGURE 1 ABOUT HERE>}

Since our results are robust to the number of portfolios, we concentrate on the 20-portfolio results. The solid line in the graphs draws the security market line (SML) predicted by the CAPM. The dashed line draws the empirical relation between average excess return and market beta by fitting a regression line to the displayed data points. For all sorts, we observe the anomalies noted in other studies. From the scatter plot for quantile portfolios of funds based on market beta, we see that the risk-return relation is somewhat flatter than the SharpeLintner $(1964,1965)$ CAPM predicts, i.e., funds that hold stocks with high (low) betas earn returns that are too low (high), given their betas. We also observe evidence of the small firm-effect documented by Banz (1981), Reinganum (1981), 
and Brav et al (2005). The empirical SML is steeper than the CAPM prediction. Funds that have the lowest exposure to the size factor (data points to the left in the plot) earn excess returns that are too low, given their market betas, and funds with the highest exposure to the size factor (data points to the right in the plot) earn excess returns that are too high. Portfolios developed from sorts on exposure to the value factor also display a large variation in excess returns that is not explained by differences in market beta. Funds that follow a value-oriented style (data points to the left in the plot) have a substantially lower market beta than do funds with a growth style (data points to the right in the plot), but earn higher excess returns. Most important, we observe the momentum effect. Funds that hold stocks that did well over the past year earn abnormal positive returns in the near future, and funds that hold stocks that did poorly earn abnormal negative returns.

Next, we perform time-series regressions in the spirit of Black et al. (1972), and use OLS to run CAPM regressions as in Equation (1) for all style portfolios over the entire post-ranking period. Table I reports the parameter estimates and $\mathrm{R}$-squared values for sorts into ten style portfolios.

\section{$<$ INSERT TABLE I ABOUT HERE>}

Figure 2 presents the style portfolios' alphas that result from running the CAPM regressions for sorts into 20 portfolios. Again, both for sorts on market beta, size beta, value beta, and past returns our results are consistent with the style anomalies noted in other studies. The portfolios' alphas increase with the quantile ranks when we sort funds on their market betas. For sorts on exposure to the size factor, we observe evidence of the small-firm effect. We also see that alphas decrease with the quantile ranks when we sort funds on exposure to the value factor and past returns. On a yearly basis, the spread in alpha between the top and bottom deciles is about $1.3 \%$ to $2.4 \%$ for sorts on market, size, and value beta. For sorts on past return, this spread even mounts to more than $11 \%$. 
We use the pooled time-series-cross-sectional methodology of Gibbons et al. (1989) to test whether the style portfolios' alphas are jointly equal to zero, and whether the portfolios' returns are fully described by a linear function of their market betas. Formally, the condition that we test for is given by:

$$
E\left(r_{i}\right)=\beta_{i} E\left(r_{m}\right)
$$

where $E\left(r_{i}\right)$ is the expected return on portfolio $i$ in excess of the risk-free rate, $E\left(r_{m}\right)$ is the expected return on the market portfolio in excess of the risk-free rate, and $\beta_{i}=\operatorname{cov}\left(r_{i}, r_{m}\right) / \operatorname{var}\left(r_{m}\right)$. We compute the Gibbons-Ross-Shanken (1989) statistic as:

$$
G R S \equiv\left(\frac{T-N-1}{N}\right) \hat{\alpha}^{\prime}\left[\left(1+\frac{\bar{r}_{m}}{\hat{\sigma}_{m}}\right)^{2} \hat{\Sigma}\right]^{-1} \hat{\alpha}
$$

where $\hat{\alpha}$ is a $N$ by 1 vector of estimated alphas, $\hat{\Sigma}$ is an $N$ by $N$ matrix that holds the unbiased estimate of the residual variance-covariance matrix, $\bar{r}_{m}$ is the sample mean of the excess return on the market portfolio, and $\hat{\sigma}_{m}{ }^{2}$ is an unbiased estimate of the variance of the excess return on the market portfolio. Assuming that the errors are independently and normally distributed, and uncorrelated with the returns on the market portfolio, the GRS statistic follows an F-distribution with $\mathrm{N}$ degrees of freedom in the numerator and $\mathrm{T}-\mathrm{N}-1$ degrees in the denominator under the null of zero alphas.

Apart from the GRS statistic, we also compute the following test statistic to find out if all alphas are jointly equal to zero: 


$$
T\left[\left(1+\frac{\bar{r}_{m}}{\hat{\sigma}_{m}}\right)^{2}\right]^{-1} \hat{\alpha} \hat{\Sigma}^{-1} \hat{\alpha}
$$

This test statistic does not require normality of the error terms. Assuming homoscedasticity this test statistic obeys an asymptotic $\chi^{2}$-distribution with $N$ degrees of freedom under the null of zero alphas. The results are listed in Table II. Although it seems that the empirical SML for sorts on market beta is flatter than the Sharpe-Lintner $(1964,1965)$ CAPM predicts, this deviation is not statistically significant at any conventional significance level.

\section{<INSERT TABLE II ABOUT HERE>}

There is also no strong evidence supporting the small-firm effect. The GRS test statistic indicates a significant deviation from the CAPM prediction only for the 20-portfolio data set. On the other hand, the CAPM does not appear to be able to explain the returns on the style portfolios based on value beta and past returns. Whether we use ten, 20 , or 30 portfolios, the resulting $p$-values tell a consistent story. Funds that hold value stocks have higher alphas than do funds that hold growth stocks, and funds that hold winners have higher alphas than do funds that hold losers. Neither phenomenon is explained by differences in market betas. Hence, we conclude that at least to some extent, fund managers are able to exploit the value and momentum anomalies reported in other studies. For the value premium, this conclusion is less pessimistic than that of Houge and Loughran (2006), who propose that "the value premium is simply beyond the reach of investors." Although momentum profits have been labeled "illusory" by Lesmond et al. (2004), Korajczyk and Sadka (2006) argue that transaction costs, in the form of spreads and price impacts of trades, do not fully explain the return persistence of past winner stocks. ${ }^{2}$

\footnotetext{
${ }^{2}$ Several studies indicate that there is a large dispersion in transaction costs for different investment styles (Keim and Madhaven, 1997), and that the size, value and momentum anomalies are concentrated in small cap stocks (see e.g., Loughran (1997), Hong et al. (2000),
} 


\section{B. The SMB, HML and WML factor proxies}

We relate the factor premiums fund managers actually earn to their factor betas, and derive the implied factor returns that make these numbers consistent with each other. We then compare these values to the excess returns on the hypothetical stock portfolios RMRF, SMB, HML and WML. Here, WML (winner minus loser) is our proxy for the momentum effect documented by Jegadeesh and Titman (1993) that we use with the Carhart 4FM. ${ }^{3}$

$$
r_{i, t}=\alpha_{i}+\beta_{1, i} R M R F_{t}+\beta_{2, i} S M B_{t}+\beta_{3, i} H M L_{t}+\beta_{4, i} W M L_{t}+\varepsilon_{i, t}
$$

We perform cross-sectional Fama and MacBeth (1973) regressions. We estimate Equation (1), Equation (2), and Equation (6) for the style portfolios by using a rolling window, and solve for the expected returns for funds with unit exposure to RMRF, SMB, HML, and WML, as a function of the estimated betas from the timeseries regressions. For example, for the Carhart 4FM:

$$
\left[\begin{array}{c}
r_{\beta 1, t} \\
r_{\beta 2, t} \\
r_{\beta 3, t} \\
r_{\beta 4, t}
\end{array}\right] \equiv\left(\left[\begin{array}{c}
\hat{\beta}_{1, t-1}^{\prime} \\
\hat{\beta}^{\prime}{ }^{\prime, t-1} \\
\hat{\beta}_{3, t-1}^{\prime} \\
\hat{\beta}^{\prime}{ }_{4, t-1}
\end{array}\right]\left[\begin{array}{llll}
\hat{\beta}_{1, t-1} & \hat{\beta}_{2, t-1} & \hat{\beta}_{3, t-1} & \hat{\beta}_{4, t-1}
\end{array}\right]\right)^{-1}\left[\begin{array}{l}
\hat{\beta}^{\prime}{ }^{\prime, t-1} \\
\hat{\beta}^{\prime}{ }^{\prime, t-1} \\
\hat{\beta}^{\prime}{ }_{3, t-1} \\
\hat{\beta}^{\prime}{ }_{4, t-1}
\end{array}\right] r_{t}
$$

where $r_{t}$ is a $\mathrm{N}$ by 1 vector of excess returns on the style portfolios at time t; $\hat{\beta}_{1, t-1}, \hat{\beta}_{2, t-1}, \hat{\beta}_{3, t-1}$, and $\hat{\beta}_{4, t-1}$ are $\mathrm{N}$ by 1 vectors of the style portfolios' exposures to RMRF, SMB, HML, and WML, estimated using a 36-month rolling window that

and Post and Vliet (2005)), or stocks with higher transaction costs (see e.g., Stoll and Whaley (1983), Ali et al. (2003), Lesmond et al. (2004), Houge and Loughran (2006) and Agarwal and Wang (2007)).

${ }^{3}$ The authors would like to thank Mark Carhart for generously providing the data on the momentum factor used in Carhart (1997). 
ends at $\mathrm{t}-1$; and $r_{\beta 1, t}, r_{\beta 2, t}, r_{\beta 3, t}$, and $r_{\beta 4, t}$ are the implied excess returns for funds with unit exposure to RMRF, SMB, HML, and WML, respectively.

We perform the analysis on 30 quantile portfolios based on the factor exposure for which we want to obtain the premium. This procedure ensures that the style portfolios exhibit a large cross-sectional spread in exposure to the factor for which we estimate the premium. For example, to obtain an estimate of the size premium, we perform the cross-sectional regressions on 30 quantile portfolios of funds based on the funds' exposures to size betas. To obtain an estimate of the value premium, we perform the regressions on 30 quantiles of funds based on value beta. The style portfolios returns cover the period January 1966 to December 2003. We use the first 36 months of this period (January 1966 to December 1968) to initialize the procedure, so we obtain returns on the unitbeta style portfolios over the period January 1969 to December 2003.

First, we determine the excess returns for funds with unit exposure to RMRF as a function of the estimated betas from the CAPM regression Equation (1) for 30 quantile portfolios sorted on market beta. We find a time-series average of $0.37 \%$ per month for $r_{\beta 1, t}$ ( $t$-value of 1.59). The average excess return of the hypothetical stock portfolio RMRF over the same period is $0.42 \%$ per month ( $t$ value of 1.83). The average difference between both portfolios is about 60 basis points on a yearly basis, and is not statistically significant ( $t$-value of 1.16). Thus, we can conclude that fund managers earn a premium for exposure to the market that is statistically and economically not much different from the return projected by the hypothetical stock portfolio RMRF.

Second, we determine the excess returns for funds with unit exposure to SMB and HML as a function of the estimated betas from the Fama-French 3FM regression in Equation (2) for 30 quantile portfolios based on size beta and value beta, respectively. We find a time-series average of $0.11 \%$ per month for $r_{\beta 2, t}(t$ value of 0.62 ), which is only slightly lower than the size premium based on SMB of $0.13 \%$ per month ( $t$-value of 0.78 ). However, the average return of $0.16 \%$ per month ( $t$-value of 0.97$)$ for $r_{\beta 3, t}$ is substantially lower than the return of $0.43 \%$ per 
month ( $t$-value of 2.83) projected by HML. Although the hypothetical hedge portfolio $\mathrm{HML}$ indicates that the value premium is more than $5 \%$ on a yearly basis, $r_{\beta 3, t}$ indicates that fund managers with unit exposure to HML earn a return of only $2 \%$ per year. The $t$-value of the difference between $r_{\beta 3, t}$ and HML is 2.86. These results indicate that fund managers who follow a value-oriented style earn returns that are too high, given their market betas, but that the abnormal returns are smaller than projected by the hypothetical hedge portfolio HML.

We solve for the expected returns for a fund with unit exposure to WML as a function of the estimated betas in Equation (6) for 30 quantile portfolios based on past returns. We find an average value of $1.64 \%$ per month for $r_{\beta 4, t}(t$-value of 4.13), even though $W M L$ indicates that the momentum effect is only $0.94 \%$ per month ( $t$-value of 3.72). The $t$-value of the difference between $r_{\beta 4, t}$ and WML is 1.98. These results indicate that the actual return differential between past winners and losers is larger than implied by the hypothetical hedge portfolio WML.

To make the estimated WML factor loadings consistent with the spread in average returns for funds sorted on past return, the average excess return on the factor should be $19 \%$ rather than $11 \%$ per year. However, we stress that we do not observe a $19 \%$ difference in returns between certain groups of funds. Rather, it reflects the excess returns of a hypothetical mutual fund with a loading of one on the momentum factor. We note that the results in Table III indicate that the estimated spread in momentum factor loadings is only 0.61 , which is much smaller than those for either SMB or HML.

The observation that price momentum for mutual funds is stronger than predicted by the proxy that we use with multifactor approaches has also been documented by Wermers (2003) who studies mutual fund portfolio holdings. The author argues that because winning funds have correlated holdings, they appear to push up stock prices through their flow-related purchases of the same stocks. On the other hand, losing managers are reluctant to sell their low return stocks and replace them with new momentum stocks. Thus, momentum works against 
them, because they hold on to losers that continue to be losers. As a result, the persistence in fund returns is not entirely explained by the momentum factor.

\section{Using index funds to estimate the factor premiums}

Another way to correct for transaction costs when estimating the factor premiums is to look at the net returns of index funds that closely track the hypothetical stock portfolios. Baks et al. (2001) propose to take the low-cost index funds from the Vanguard mutual fund family as investable alternatives for RMRF, SMB, and HML. As pointed out by Baks et al. (2001), there are no lowcost index alternatives available for WML, since momentum strategies have high turnover by nature. We extract return data from CRSP for Vanguard's index funds offered for the overall market, small-cap value, small-cap neutral, small-cap growth, large-cap value, large-cap neutral and large-cap growth. First, we perform a simple linear regression of the excess returns of the Vanguard Total Stock Market Index fund on RMRF. The resulting return series covers the fund's inception date, May 1992, to December 2003. The estimated intercept in this regression of $0.0007 \%$ is consistent with our earlier finding that fund managers earn a premium for exposure to the market that is basically the same as the return projected by RMRF.

To obtain investable alternatives for SMB and HML, we build portfolios of the index funds. We take the return differential between the average returns of the funds in the small cap and large cap categories for SMB, and the return differential between the average returns of the value and growth categories for HML. The resulting return series covers the period December 1992 to December 2003. We perform linear regressions of the portfolios' returns on SMB and HML. For the regression on SMB, the estimated intercept is $-0.06 \%$, and for $\mathrm{HML}$ the intercept is $-0.25 \%$. These results are similar to those we obtained from the cross-sectional regressions. Our findings indicate that the actual size premium is similar to the return projected by SMB, but the hypothetical hedge portfolio HML overestimates the value premium by about $3 \%$ per year. 


\section{Multifactor performance estimates}

Although we find a value premium and a momentum effect in the crosssection of fund returns, the premiums that fund managers actually earn for exposure to these factors are different from the returns projected by the usual proxies that researchers use with multifactor approaches.

The second objective of this study is to investigate how this miscalculation of the factor premiums affects the cross-sectional explanatory power of the Fama-French 3FM and the Carhart 4FM we introduced earlier. To investigate this issue, we consider the style portfolios' alphas resulting from the Fama-French 3FM in Equation (2) and the Carhart 4FM in Equation (6). Table III lists the alpha estimates for all style portfolios.

\section{$<$ INSERT TABLE III ABOUT HERE>}

The table shows that for sorts on market beta, value beta, and past returns, the alphas still point to distinctive patterns from one decile rank to another. For sorts on market and value beta, we now observe a contrary pattern: funds with low market beta appear to have lower alphas than do those with high market beta, and growth funds appear to have higher alphas than do value funds.

For sorts on past returns, Fama-French 3FM alphas exhibit the same pattern as CAPM alphas, and have the same order of magnitude. In economic terms, the spreads between the top and bottom deciles are substantial. On a yearly basis, the spread in alpha between the top and bottom deciles for sorts on value beta is about $3.6 \%$, and this spread mounts up to more than $12 \%$ for sorts on past returns.

When we consider the Carhart 4FM results, we find basically the same patterns for sorts on market and value beta. For sorts on past returns, past losers still underperform past winners, but the spread between the top and bottom deciles is smaller than for the Fama-French 3FM results. However, this spread is still more than $3.5 \%$ per year. Although past winners have positive alphas, these deviations are only marginally significant. For losers, the returns predicted by the 
Carhart 4FM are substantially higher than are those generated by the fund managers.

To test whether the alphas are jointly equal to zero, we perform multivariate extensions to the test statistics we introduced previously:

$$
G R S \equiv\left(\frac{T-N-K}{N}\right)\left(1+\hat{\mu}^{\prime} \hat{\Omega}^{-1} \hat{\mu}\right)^{-1} \hat{\alpha}^{\prime} \hat{\Sigma}^{-1} \hat{\alpha} \sim F(N, N-T-K)
$$

and

$$
T\left(1+\hat{\mu}^{\prime} \hat{\Omega}^{-1} \hat{\mu}\right)^{-1} \hat{\alpha}^{\prime} \hat{\Sigma}^{-1} \hat{\alpha} \sim \chi_{N}^{2}
$$

where $\hat{\mu}$ is a $\mathrm{K}$ by 1 vector of sample means of the style portfolios' excess returns, $\hat{\Omega}$ is a K by K matrix that holds the unbiased estimate of the factor portfolios covariance matrix, and $\mathrm{K}$ is the number of benchmark factors that we use in the factor model. The resulting test statistics and the accompanying $p$ values are presented in Table IV.

\section{<INSERT TABLE IV ABOUT HERE>}

We first examine the results for the Fama-French 3FM. For sorts on market and size beta, the null of zero alphas is not rejected in all cases, except for sorts in 20 portfolios based on size beta. For sorts into 30 portfolios, the results are mixed. However, for sorts on value beta and past returns, the null is clearly rejected. When we consider the Carhart 4FM results, the results are not much different: the null of zero alphas is rejected for sorts on value beta for all analyses, and for sorts into ten and 20 quantiles that sort on past returns.

Apparently, both the Fama-French 3FM and the Carhart 4FM are unable to explain the cross-section of fund returns for sorts on value beta and past returns. Finding that the Fama-French 3FM cannot explain the returns of style 
portfolios sorted on past returns is as we expected, since the model makes no attempt to control for the momentum effect. However, both the Fama-French 3FM and the Carhart 4FM explicitly attempt to correct for the value premium. The perverse patterns in the style portfolios' alphas for sorts on value beta is consistent with our finding that the premium that fund managers actually earn for following a value-oriented style is smaller than is the return projected by the hypothetical hedge portfolio HML. Also, the return differential between past winners and losers that the Carhart 4FM cannot explain is consistent with our previous finding that the hypothetical hedge portfolio WML underestimates the momentum effect for mutual funds.

\section{Robustness}

Here, we investigate the robustness of our results to time-varying market betas, alternative cut-off points for computing factor premiums, and differences in the funds' expense ratios.

\section{A. Robustness to time-varying market betas}

First, we investigate the robustness of our results to time-varying market betas. Similar to Ferson and Schadt (1996) and Ferson and Harvey (1999), we estimate the style portfolios' alphas by using a conditional CAPM. Doing so allows the market betas to vary over time, conditional on a set of predetermined variables:

$$
r_{i, t}=\alpha_{i}+\beta_{i} R M R F_{t}+B_{i}^{\prime}\left[z_{t-1} R M R F_{t}\right]+\varepsilon_{i, t}
$$

where $z_{t-1}$ denotes a vector holding the lagged values of the information variables, and the vector $B_{i}^{\prime}$ captures the response of portfolio i's market beta to benchmark $j$ to this information. We use the following information variables: the lagged level of the one-month Treasury bill yield, the lagged dividend yield of the CRSP value-weighted market index, a lagged measure of the slope of the term 
structure of interest rates, a lagged default spread in the corporate bond market, and a January dummy. We define the dividend yield as the dividend per share, which is a percentage of the share price over the past 12 months for the index. We define the term spread as a constant-maturity ten-year Treasury bond yield minus the one-month Treasury bill yield, and define the default spread as Moody's BAA-rated corporate bond yield minus the AAA-rated corporate bond yield. We obtain the dividend yield data from Wharton Research Data Services (WRDS), and the bond yield data from the webpage of the Federal Reserve Bank. The resulting factor model includes six scaled factors and an intercept. We also use a conditional version of the Fama-French 3FM and the Carhart 4FM, which augment the conditional CAPM with factors for size, value, and momentum:

$$
r_{i, t}=\alpha_{i}+\beta_{i} R M R F_{t}+B_{1 i}^{\prime}\left[z_{t-1} R M R F_{t}\right]+\beta_{2, i} S M B_{t}+\beta_{3, i} H M L_{t}+\varepsilon_{i, t}
$$

and

$$
r_{i, t}=\alpha_{i}+\beta_{i} R M R F_{t}+B_{1 i}^{\prime}\left[z_{t-1} R M R F_{t}\right]+\beta_{2, i} S M B_{t}+\beta_{3, i} H M L_{t}+\beta_{4, i} W M L_{t}+\varepsilon_{i, t}
$$

We use OLS to estimate the style portfolios' alphas using the three conditional models over the entire post-ranking period, and test whether the alphas are jointly equal to zero. The results for sorts into decile portfolios are presented in Table V.

\section{<INSERT TABLE V ABOUT HERE>}

The alpha estimates for the conditional models are similar to those for the unconditional models. The null hypothesis of zero alphas is rejected for sorts on value beta, and past return, and marginally rejected for sorts on size beta. For the conditional CAPM, we find the same pattern as for unconditional CAPM regressions: funds that follow a value (growth) oriented style earn returns that are too high (low) given their betas, and funds that hold stocks that did well (poorly) 
in the past year earn abnormal positive (negative) returns in the near future. Including the SMB, HML, and WML factors leads to the same patterns we find for the unconditional multifactor models.

Performance estimates for value funds and past losers are biased downwards, and those for growth funds and past winners are biased upwards. In economic terms, the spreads between alphas of the top and bottom deciles have the same order of magnitude as do those reported earlier for the unconditional models. Thus, our results indicate that the anomalies cannot be explained by conditional models that allow for time-varying market betas.

\section{B. Robustness to alternative cut-off points for computing factor premiums}

An alternative explanation for our results could be that the specific cut-off points we use to construct the factor proxies do not produce portfolios that closely correspond to the holdings of many mutual funds. For example, the WML factor uses cut-offs corresponding to the 70th and 30th percentiles for sorts on past returns. However, funds might focus on more extreme percentiles, holding stocks in the 90th and 10th percentiles. If there are larger return differences in the more extreme tails of the distribution based on past return, then an alternative momentum factor based on more extreme percentiles could lead to performance estimates that are not positive to the degree they are when we use the standard 70-30 WML factor. Funds might also focus on less extreme book-to-marketequity stocks, so that an alternative value factor based on less extreme deciles could lead to performance estimates that on average are not negative. ${ }^{4}$

To investigate this issue, we perform a style analysis and test whether funds that under- or outperform relative to the factor models do indeed focus on more or less extreme style percentiles. Table VI shows the correlations between the decile portfolios of funds for sorts on value beta and past returns. We obtain the return data on the decile portfolios of stocks from the data library of French (2004). For example, Panel A shows that the correlation between the top decile of fund sorted on value beta D1 and the top decile of stocks sorted on book-to-

\footnotetext{
${ }^{4}$ We thank an anonymous referee for this explanation.
} 
market-equity B2M1 (i.e., value stocks) is 0.9 , but the correlation with the bottom decile of stocks sorted on book-to-market-equity B2M10 (i.e., growth stocks) is 0.67 .

\section{<INSERT TABLE VI ABOUT HERE>}

If the underperformance of value-oriented funds relative to the FamaFrench 3FM and the Carhart 4FM is due to the funds' focusing on less extreme book-to-market-equity stocks, then we expect to find that the correlation between the top decile of funds sorted on value beta D1 will be the strongest with less extreme deciles of stocks sorted on book-to-market-equity (e.g., B2M5, and B2M6). However, the results point to the opposite: funds appear to focus on more extreme deciles of stocks sorted on book-to-market-equity. Except for the decile of funds with the lowest value betas D10, all the deciles have the strongest correlation with the more extreme deciles of stocks sorted on book-to-marketequity B2M1, B2M2, and B2M3. Hence, we conclude that underperformance of value funds relative to the multifactor models is not due to funds focusing on less extreme book-to-market-equity stocks.

We perform a similar analysis to test whether the outperformance of winner funds relative to the Fama-French 3FM and the Carhart 4FM could be due to the funds' focusing on more extreme percentiles of stocks sorted on past return. The results in Panel $B$ indicate that mutual funds do focus on more extreme stocks. For example, the top three deciles of funds sorted on past returns have the strongest correlations with the top decile of stocks sorted on past return (e.g., 0.93, 0.94, and 0.93).

To investigate whether funds that focus on more extreme momentum stocks explain our results, we construct a more extreme momentum factor WML , using cutoff points corresponding to the 90th and 10th percentiles of stocks sorted on past return. We then run Carhart 4FM regressions on the style portfolios of funds for sorts on past returns, using this alternative factor to proxy for the momentum effect. The results in Table VII show that the Carhart 4FM 
alphas exhibit the same pattern as before and have the same order of magnitude. In fact, on a yearly basis, the spread in alpha between the top and bottom deciles is now even more than $4 \%$. The multivariate test statistics in Equations (8) and (9) also strongly reject the null of zero alphas. We find a $\chi^{2}$-value of 21.85 with a $p$ value of 0.02 and a GRS F-statistic of 2.12 with a p-value of 0.02 .

These results indicate that funds do indeed appear to focus on more extreme momentum stocks, but that our findings are robust to a momentum factor with more extreme cutoff points.

\section{$<$ INSERT TABLE VII ABOUT HERE>}

\section{Robustness to differences in fund expenses}

Differences in expense ratios might explain part of the patterns in alphas for the style portfolios. To investigate this issue, we examine the pre-expense returns of the style portfolios. We obtain pre-expense returns for every month by adding back one-twelfth of the yearly expense ratio reported by the funds in the respective year to the funds' returns.

Table VIII illustrates the interaction of the patterns in post-expense alphas with expense ratios by showing the expense ratios and pre-expense alphas across the style portfolios. Although adding back the fund expenses obviously leads to higher (less negative) alphas, the spread in alphas and their patterns are hardly affected. For example, after adding back fund expenses, the spread in Carhart 4FM alphas between the top and bottom deciles for sorts on value beta and past returns are about $2.7 \%$ and $3.6 \%$, respectively. We conclude that differences in expenses play a very limited role.

<INSERT TABLE VIII ABOUT HERE>

\section{Factor proxies based on mutual fund returns provide better benchmarks}

Because the use of the standard SMB, HML, and WML factors in a multifactor performance evaluation model leads to systematic biases in mutual 
fund alphas, we explore alternative factor models that do not suffer from this drawback. One approach is to construct new factor-mimicking portfolios that use spreads and price impact of trades to take into account transaction costs. Given the nonproportional and asymmetric nature of the latter this is a nontrivial exercise (see, e.g., Korajczyk and Sadka (2006)). Instead, we use a simpler and more direct approach by construct factors by using returns from portfolios of mutual funds. The advantage of this approach is that the factor returns are based on actually realized returns by institutional investors. Furthermore, as argued by Hendricks et al. (1993), another reason to believe that composite factors might provide better benchmarks than hypothetical stock portfolios is that some priced factors are unknown to the econometrician or not agreed upon by the finance profession. The disadvantage is that the alphas from such factor models are necessarily a relative performance measure, relative to the cross-section of mutual funds. If, for example, all funds were to charge exceptionally high expenses, doing so would not reduce performance measures accordingly. Alternatively, if the average mutual fund were to possess true managerial skill (and produce positive alphas for a relevant set of factors), our approach would reflect only the different skills of each fund manager, not the overall level. However, given that most empirical studies find little or no evidence of managerial skill combined with the size and highly competitive nature of the industry, we feel that these drawbacks might play only a minor role.

We set the first factor, which acts as a proxy for a broad market portfolio, to the average return for all available funds at each period in time. We construct the factor proxies for size, value, and momentum, as follows. Each month, we estimate the Fama-French 3FM in Equation (2) for all available funds by using OLS with a rolling window over the preceding 36 months. We define our size proxy as the average return of all funds with estimated $\beta_{2, i}$ above the size breakpoint minus the average return of all funds with $\beta_{2, i}$ equal or below the breakpoint; our value proxy as the average return of all funds with $\beta_{3, i}$ above the value breakpoint minus the average return of all funds with $\beta_{3, i}$ equal or below 
the breakpoint; and our momentum proxy as the average return of all funds with 12-month returns above the momentum breakpoint minus the average return of all funds below the breakpoint. We set the size breakpoint to the median loading on SML, the value breakpoint to the median loading on HML, and the momentum breakpoint to the median fund return over the past 12 months. To ensure that the results are robust to our choice of the breakpoints, we also construct factors for which we set the breakpoints to the 33rd and 67th percentile loading on SML and HML and fund return over the past 12 months, and the 20th and 80th percentile loading on SML and HML and fund return over the past 12 months.

Although the resulting proxies for size, value and momentum are noninvestable, we argue that if the biases in the multifactor performance estimates are indeed due to miscalculation of the factor premiums, then these proxies might yield better results, since they are based on net fund returns, and therefore incorporate transaction costs and trading restrictions.

We compute the style portfolios' alphas resulting from Fama-French 3FM and Carhart 4FM specifications by using factor proxies based on fund returns, and test if the resulting alphas are jointly equal to zero using the multivariate test statistics in Equations (8) and (9). Table IX shows the resulting alphas and test statistics for the decile style portfolios.

\section{<INSERT TABLE IX ABOUT HERE>}

When we consider the results for sorts on value beta, we find that the contrary pattern in the deciles' alphas has disappeared. In fact, we do not see any pattern at all. The alphas are also small from an economic point of view. Furthermore, the tests indicate that the null of zero alphas cannot be rejected for any reasonable level of significance. These results hold regardless of how we define the factors' breakpoints.

When we examine the results for sorts on past returns, we find that the observation that the Fama-French 3FM cannot explain the returns of style portfolios sorted on past returns is again as we expected, since the Fama-French 
3FM makes no attempt to control for this effect. However, because the corresponding alphas are not significantly different from zero, it appears that the Carhart 4FM model is able to cope with the momentum effect. Again, the results hold irrespective of how we define the factors' breakpoints.

Our findings indicate that factor proxies based on mutual fund returns rather than stock returns provide better benchmarks to evaluate professional money managers. That is, any patterns or systematic biases in the four-factor alphas disappear with the use of factor proxies based on fund returns rather than stock returns.

\section{Conclusion}

In this paper we provide evidence that market betas by themselves do not suffice to describe the cross-section of fund returns. We use the Gibbons et al. (1989) pooled time-series-cross-sectional test method to test whether CAPM alphas of style portfolios of funds based on market beta, size beta, value beta, and past returns are jointly equal to zero. We reject the null of zero alphas for sorts on value beta and past returns. Funds with a value (growth) oriented style, and funds that hold stocks that do well (poorly) over the past year, earn returns that are higher (lower) than predicted by the CAPM. The funds' alphas are up to more than $6 \%$ per year. Our findings indicate that the value premium and the momentum effect reported in other studies are economically significant, and persist beyond transaction costs and trading restrictions.

However, the premiums that fund managers actually earn for exposure to these factors are different from the returns implied by the typical proxies that are used with the multifactor approaches. The value premium in the cross-section of fund returns is smaller than predicted by the hypothetical hedge portfolio HML. Further, the return differential between past winners and losers is much larger than predicted by the hypothetical hedge portfolio WML.

This miscalculation of the factor premiums affects the cross-sectional explanatory power of multifactor models to evaluate mutual fund performance. We find that the usual three- and four-factor alphas do not adequately control for 
the anomalies. In particular, multifactor performance estimates for value funds and past losers are biased downwards, and those for growth funds and past winners are biased upwards. These results are robust to time-varying betas.

Irrespective of the question whether the SMB, HML, and WML factors are inappropriate due to transaction costs, trade impact, trading restrictions, or other causes, our results suggest that some caution is warranted in applying the standard three- and four-factor performance attribution models to mutual funds, because the performance of certain types of funds is systematically over- or underestimated.

One alternative that does not suffer from these biases is based on the use of a four-factor model in which we construct the factors by using mutual fund returns rather than stock returns. The alphas that result from this model do not exhibit systematic patterns and appear to provide unbiased estimates of a fund manager's performance. 


\section{References}

Agarwal, V. , and L. Wang, 2007, "Transaction costs and value premium," Working paper Georgia State University.

Ali, A., L. Hwang and M. A. Trombley, 2003, "Arbitrage risk and the book-tomarket anomaly," Journal of Financial Economics, 69:355-373.

Baks, K. P., A. Metrick, and J. Wachter, 2001, "Should investors avoid all actively managed mutual funds? A study in Bayesian performance evaluation," Journal of Finance, 56:45-85.

Banz ,R. W., 1981, "The relationship between return and market value of common stocks," Journal of Financial Economics, 9:3-18.

Black, F. , M. C. Jensen, and M. Scholes, 1972, The Capital Asset Pricing Model: Some Empirical Tests, Praeger, New York.

Bollen, N. P. B., and J. A. Busse, 2005, "Short-term persistence in mutual fund performance," Review of Financial Studies, 18:569-597.

Brav, A. , R. Lehavy, and R. Michaely, 2005, "Using expectations to test asset pricing models," Financial Management, 34:31-64.

Brown, S. J., and W. Goetzmann, 1995, "Performance persistence," Journal of Finance, 50:679-698.

Brown, S. J., W. Goetzmann, R. G. Ibbotson, and S. A. Ross, 1992, "Survivorship bias in performance studies," Review of Financial Studies, 5:553-580.

Carhart, M., 1997, "On persistence in mutual fund performance," Journal of Finance, 52:57-82. 
Coles, J. L., N. D. Daniel, and F. Nardari, 2006, "Does the choice of model or benchmark affect inference in measuring mutual fund performance?" Working paper Arizona State University.

Fama, E. F., and K. R. French, 1993, "Common risk factors in the returns on stocks and bonds," Journal of Financial Economics, 33:3-56.

Fama, E. F., and K. R. French, 1995, "Size and book-to-market factors in earnings and returns," Journal of Finance, 50:131-155.

Fama, E. F., and K. R. French, 1996, "Multifactor explanations of asset pricing anomalies," Journal of Finance, 1:55-84.

Fama, E. F., and J. D. MacBeth, 1973, "Risk, return, and equilibrium: Empirical tests," Journal of Political Economy, 81:607-636.

Ferson, W. E., and C. R. Harvey, 1999, "Conditioning variables and the crosssection of stock returns," Journal of Finance, 54:1325-1360.

Ferson, W. E., and R. W. Schadt, 1996, "Measuring fund strategy and performance in changing economic conditions," Journal of Finance, 51:425-461.

French, K.R., Fama-French Factors, 2004, Retrieved January 28, 2004, from http://mba.tuck.dartmouth.edu/pages/faculty/ken.french/data_library.html

Gibbons, M. R., S. A. Ross, and J. Shanken, 1989, "A test of effciency of a given portfolio," Econometrica, 57:1121-1152.

Grinblatt, M., and S. Titman, 1994, "A study of monthly mutual fund returns and performance evaluation techniques," Journal of Financial and Quantitative Analysis, 29:419-444. 
Hendricks, D., J. Patel, and R. Zeckhauser, 1993, "Hot hands in mutual funds: Short-run persistence of relative performance, 1974-1988," Journal of Finance, 48:93-130.

Hong, H., T. Lim, and J. C. Stein, 2000, "Bad news travels slowly: Size, analyst coverage, and the profitability of momentum strategies," Journal of Finance, 55:265-295.

Houge, T., and T. Loughran, 2006, "Do investors capture the value premium?" Financial Management, 35:5-19.

Jegadeesh, N., and S. Titman, 1993, "Returns to buying winners and selling losers: Implications for stock market efficiency," Journal of Finance, 48:65-91.

Jensen, M. C., 1968, "The performance of mutual funds in the period 1945-1964", Journal of Finance, 23:389-416.

Keim, D. B., and A. Madhaven, 1997, "Transactions costs and investment style: An inter-exchange analysis of institutional equity trades," Journal of Financial Economics, 46:265-292.

Korajczyk, R., and R. Sadka, 2006, "Are momentum profits robust to trading costs?" Journal of Finance, 59:1039-1082.

Lehman, B. N., and D. M. Modest, 1987, "Mutual fund performance evaluation: A comparison of benchmarks and benchmark comparisons," Journal of Finance, 42:233-265.

Lesmond, D. A., M. J. Schill, and C. Zhou, 2004, "The illusory nature of momentum profits," Journal of Financial Economics, 71:349-380.

Lintner, J., 1965, "The valuation of risk assets and the selection of risky investments in stock portfolios and capital budgets," Review of Economics and Statistics, 47:13-37. 
Loughran, T., 1997, "Book-to-market across firm size, exchange, and seasonality: Is there an effect?" Journal of Financial and Quantitative Analysis, 32:249-268.

Pastor, L., and R. F. Stambaugh, 2002a, "Investing in equity mutual funds," Journal of Financial Economics, 63:351-380.

Pastor, L., and R. F. Stambaugh, 2002b, "Mutual fund performance and seemingly unrelated assets," Journal of Financial Economics, 63:315-349.

Post, T., and W. V. Vliet, 2005, "Do multiple factors help or hurt?" Working paper Erasmus University Institute of Management.

Reinganum, R., 1981, "Misspecification of capital asset pricing: Empirical anomalies based on earnings yields and market values," Journal of Financial Economics, 9:19-46.

Roll, R., 1978, "Ambiguity when performance is measured by the securities market line," Journal of Finance, 33:1051-1069.

Sharpe, W. F. , 1964, "Capital asset prices: A theory of market equilibrium under conditions of risk," Journal of Finance, 19:425-442.

Stoll, H. R., and R. E. Whaley, 1983, "Transactions costs and the small firm effect," Journal of Financial Economics, 12:57-79.

Wermers, R. , 2003, "Is money really "smart"? New evidence on the relation between mutual fund flows, manager behavior, and performance persistence," Working paper University of Maryland. 


\section{Table I. Single-factor CAPM regressions}

We obtain our data on returns of mutual funds from the 2003 CRSP Mutual Fund Survivor-Bias-Free Database. Our sample comprises 7,852 U.S. equity funds over the period 1963-2003. We sort funds into 10 quantile portfolios based on the market beta, size beta, value beta, and past returns of their stock holdings. For the resulting style portfolios, we run single-factor CAPM regressions. The table lists the portfolios' post-ranking returns, Sharpe ratios, CAPM parameter estimates, and R-squared values. All values are annualized.

\begin{tabular}{|c|c|c|c|c|c|c|}
\hline & Return & Sharpe & Alpha & Alpha-t & RMRF & Rsq \\
\hline \multicolumn{7}{|c|}{ Sorts on market beta } \\
\hline D1 & $6.00 \%$ & 0.24 & $-1.13 \%$ & -0.66 & 1.40 & 0.82 \\
\hline D2 & $5.62 \%$ & 0.28 & $-0.47 \%$ & -0.41 & 1.20 & 0.88 \\
\hline D3 & $4.92 \%$ & 0.27 & $-0.75 \%$ & -0.87 & 1.11 & 0.92 \\
\hline D4 & $4.85 \%$ & 0.29 & $-0.45 \%$ & -0.81 & 1.04 & 0.96 \\
\hline D5 & $4.65 \%$ & 0.29 & $-0.40 \%$ & -0.66 & 0.99 & 0.95 \\
\hline D6 & $4.24 \%$ & 0.28 & $-0.52 \%$ & -1.30 & 0.93 & 0.97 \\
\hline D7 & $4.78 \%$ & 0.33 & $0.22 \%$ & 0.42 & 0.89 & 0.95 \\
\hline D8 & $4.47 \%$ & 0.32 & $0.18 \%$ & 0.33 & 0.84 & 0.94 \\
\hline D9 & $4.11 \%$ & 0.32 & $0.23 \%$ & 0.37 & 0.76 & 0.91 \\
\hline D10 & $2.92 \%$ & 0.30 & $0.18 \%$ & 0.24 & 0.54 & 0.78 \\
\hline \multicolumn{7}{|c|}{ Sorts on size beta } \\
\hline D1 & $6.10 \%$ & 0.28 & $0.01 \%$ & 0.00 & 1.20 & 0.79 \\
\hline D2 & $6.00 \%$ & 0.31 & $0.40 \%$ & 0.31 & 1.10 & 0.84 \\
\hline D3 & $5.73 \%$ & 0.32 & $0.39 \%$ & 0.42 & 1.05 & 0.90 \\
\hline D4 & $5.08 \%$ & 0.31 & $0.05 \%$ & 0.07 & 0.99 & 0.93 \\
\hline D5 & $4.75 \%$ & 0.31 & $-0.09 \%$ & -0.17 & 0.95 & 0.96 \\
\hline D6 & $4.38 \%$ & 0.29 & $-0.27 \%$ & -0.51 & 0.91 & 0.95 \\
\hline D7 & $4.05 \%$ & 0.28 & $-0.53 \%$ & -1.25 & 0.90 & 0.97 \\
\hline D8 & $3.88 \%$ & 0.27 & $-0.55 \%$ & -1.36 & 0.87 & 0.97 \\
\hline D9 & $3.39 \%$ & 0.24 & $-1.07 \%$ & -2.57 & 0.87 & 0.97 \\
\hline D10 & $3.17 \%$ & 0.21 & $-1.35 \%$ & -1.76 & 0.89 & 0.90 \\
\hline
\end{tabular}


Table I. Single-factor CAPM regressions (Continued)

\begin{tabular}{|c|c|c|c|c|c|c|}
\hline & Return & Sharpe & Alpha & Alpha-t & RMRF & Rsq \\
\hline \multicolumn{7}{|c|}{ Sorts on value beta } \\
\hline D1 & $5.55 \%$ & 0.39 & $1.57 \%$ & 1.46 & 0.78 & 0.78 \\
\hline D2 & $5.57 \%$ & 0.40 & $1.44 \%$ & 1.75 & 0.81 & 0.87 \\
\hline D3 & $4.89 \%$ & 0.35 & $0.62 \%$ & 0.87 & 0.84 & 0.90 \\
\hline D4 & $4.25 \%$ & 0.29 & $-0.25 \%$ & -0.46 & 0.88 & 0.94 \\
\hline D5 & $4.19 \%$ & 0.28 & $-0.58 \%$ & -1.23 & 0.94 & 0.96 \\
\hline D6 & $4.13 \%$ & 0.26 & $-0.82 \%$ & -1.61 & 0.97 & 0.96 \\
\hline D7 & $4.12 \%$ & 0.25 & $-1.08 \%$ & -1.84 & 1.02 & 0.95 \\
\hline D8 & $3.93 \%$ & 0.22 & $-1.50 \%$ & -2.05 & 1.07 & 0.93 \\
\hline D9 & $4.24 \%$ & 0.22 & $-1.52 \%$ & -1.61 & 1.13 & 0.91 \\
\hline D10 & $5.78 \%$ & 0.25 & $-0.85 \%$ & -0.55 & 1.30 & 0.83 \\
\hline \multicolumn{7}{|c|}{ Sorts on past return } \\
\hline D1 & $11.19 \%$ & 0.58 & $5.66 \%$ & 3.26 & 1.03 & 0.68 \\
\hline D2 & $8.91 \%$ & 0.52 & $3.51 \%$ & 3.17 & 1.00 & 0.84 \\
\hline D3 & $7.07 \%$ & 0.45 & $1.86 \%$ & 2.52 & 0.97 & 0.91 \\
\hline D4 & $5.64 \%$ & 0.37 & $0.45 \%$ & 0.82 & 0.96 & 0.95 \\
\hline D5 & $4.58 \%$ & 0.30 & $-0.59 \%$ & -1.18 & 0.96 & 0.96 \\
\hline D6 & $4.36 \%$ & 0.29 & $-0.77 \%$ & -1.54 & 0.95 & 0.96 \\
\hline D7 & $3.52 \%$ & 0.23 & $-1.59 \%$ & -3.07 & 0.95 & 0.95 \\
\hline D8 & $2.47 \%$ & 0.16 & $-2.74 \%$ & -3.97 & 0.97 & 0.92 \\
\hline D9 & $1.47 \%$ & 0.09 & $-3.76 \%$ & -4.41 & 0.97 & 0.89 \\
\hline D10 & $-0.93 \%$ & -0.05 & $-6.09 \%$ & -4.41 & 0.96 & 0.75 \\
\hline
\end{tabular}




\section{Table II. Univariate test results for zero alphas}

We obtain our data on returns of mutual funds from the 2003 CRSP Mutual Fund Survivor-Bias-Free Database. Our sample comprises 7,852 U.S. equity funds over the period 1963-2003. We sort funds into 10, 20 , and 30 quantile portfolios based on the market beta, size beta, value beta, and past returns of their stock holdings. For the resulting style portfolios, we run single-factor CAPM regressions, and test whether the estimated alphas are jointly equal to zero. The table lists the results of pooled time-series-cross-sectional tests in the spirit of Gibbons et al. (1989). p-values below the significance level of $10 \%$ appear in boldface.

\begin{tabular}{lrrrr}
\hline \hline & Chi & p-value & GRS & p-value \\
\hline$N=10$ & & & & \\
market & 6.79 & 0.74 & 0.67 & 0.76 \\
size & 11.14 & 0.35 & 1.09 & 0.37 \\
value & 21.14 & $\mathbf{0 . 0 2}$ & 2.07 & $\mathbf{0 . 0 3}$ \\
return & 27.22 & $\mathbf{0 . 0 0}$ & 2.67 & $\mathbf{0 . 0 0}$ \\
& & & & \\
\hline$N=20$ & & & & \\
market & 22.27 & 0.33 & 1.07 & 0.38 \\
size & 37.62 & $\mathbf{0 . 0 1}$ & 1.80 & $\mathbf{0 . 0 2}$ \\
value & 42.37 & $\mathbf{0 . 0 0}$ & 2.03 & $\mathbf{0 . 0 1}$ \\
return & 39.09 & $\mathbf{0 . 0 1}$ & 1.87 & $\mathbf{0 . 0 1}$ \\
& & & & \\
\hline$N=30$ & & & & \\
market & 23.94 & 0.77 & 0.75 & 0.83 \\
size & 40.33 & $\mathbf{0 . 1 0}$ & 1.26 & 0.17 \\
value & 51.27 & $\mathbf{0 . 0 1}$ & 1.60 & $\mathbf{0 . 0 3}$ \\
return & 42.96 & $\mathbf{0 . 0 6}$ & 1.34 & $\mathbf{0 . 1 1}$ \\
& & & & \\
\hline \hline
\end{tabular}




\section{Table III. Multiple-factor regressions}

We obtain our data on returns of mutual funds from the 2003 CRSP Mutual Fund Survivor-Bias-Free Database. Our sample comprises 7,852 U.S. equity funds over the period 1963-2003. We sort funds into 10 quantile portfolios based on the market beta, size beta, value beta, and past returns of their stock holdings. For the resulting style portfolios, we run Fama and French 3FM and Carhart 4FM regressions. The table lists the portfolios' post-ranking returns, Sharpe ratios, Fama and French 3FM and Carhart 4FM parameter estimates, and R-squared values. All values are annualized. 
Table III. Multiple-factor regressions (Continued)

\begin{tabular}{|c|c|c|c|c|c|c|c|c|c|c|c|c|c|}
\hline & \multicolumn{6}{|c|}{ Fama and French 3FM } & \multicolumn{7}{|c|}{ Carhart 4FM } \\
\hline & Alpha & Alpha-t & RMRF & SMB & HML & Rsq & Alpha & Alpha-t & RMRF & SMB & HML & WML & Rsq \\
\hline \multicolumn{14}{|c|}{ Sorts on market beta } \\
\hline D1 & $0.36 \%$ & 0.37 & 1.15 & 0.63 & -0.42 & 0.94 & $-0.72 \%$ & -0.73 & 1.16 & 0.65 & -0.40 & 0.08 & 0.95 \\
\hline D2 & $0.31 \%$ & 0.41 & 1.04 & 0.41 & -0.24 & 0.95 & $-0.86 \%$ & -1.18 & 1.05 & 0.43 & -0.23 & 0.08 & 0.96 \\
\hline D3 & $-0.28 \%$ & -0.41 & 1.02 & 0.25 & -0.15 & 0.95 & $-1.18 \%$ & -1.76 & 1.03 & 0.27 & -0.14 & 0.06 & 0.96 \\
\hline D4 & $-0.26 \%$ & -0.50 & 1.00 & 0.12 & -0.07 & 0.97 & $-0.74 \%$ & -1.45 & 1.00 & 0.13 & -0.06 & 0.03 & 0.97 \\
\hline D5 & $-0.55 \%$ & -0.91 & 0.98 & 0.07 & 0.00 & 0.95 & $-0.86 \%$ & -1.38 & 0.98 & 0.08 & 0.01 & 0.02 & 0.95 \\
\hline D6 & $-0.88 \%$ & -2.19 & 0.94 & 0.02 & 0.05 & 0.97 & $-0.87 \%$ & -2.12 & 0.94 & 0.02 & 0.05 & 0.00 & 0.97 \\
\hline D7 & $-0.70 \%$ & -1.39 & 0.93 & 0.02 & 0.14 & 0.96 & $-0.78 \%$ & -1.52 & 0.93 & 0.02 & 0.14 & 0.01 & 0.96 \\
\hline D8 & $-0.92 \%$ & -1.83 & 0.89 & 0.01 & 0.17 & 0.95 & $-1.05 \%$ & -2.04 & 0.89 & 0.01 & 0.17 & 0.01 & 0.95 \\
\hline D9 & $-1.18 \%$ & -2.18 & 0.81 & 0.04 & 0.21 & 0.94 & $-1.32 \%$ & -2.39 & 0.81 & 0.04 & 0.21 & 0.01 & 0.94 \\
\hline D10 & $-1.57 \%$ & -2.42 & 0.60 & 0.06 & 0.26 & 0.84 & $-2.11 \%$ & -3.21 & 0.60 & 0.07 & 0.26 & 0.04 & 0.84 \\
\hline \multicolumn{14}{|c|}{ Sorts on size beta } \\
\hline D1 & $-0.86 \%$ & -0.91 & 1.02 & 0.72 & -0.08 & 0.93 & $-1.89 \%$ & -2.01 & 1.03 & 0.74 & -0.07 & 0.07 & 0.94 \\
\hline D2 & $-0.29 \%$ & -0.34 & 0.98 & 0.51 & -0.05 & 0.93 & $-1.48 \%$ & -1.77 & 0.99 & 0.54 & -0.03 & 0.09 & 0.94 \\
\hline D3 & $-0.04 \%$ & -0.06 & 0.96 & 0.36 & -0.04 & 0.95 & $-1.07 \%$ & -1.64 & 0.97 & 0.38 & -0.02 & 0.07 & 0.95 \\
\hline D4 & $-0.11 \%$ & -0.19 & 0.93 & 0.23 & -0.04 & 0.96 & $-0.96 \%$ & -1.73 & 0.94 & 0.25 & -0.03 & 0.06 & 0.96 \\
\hline D5 & $-0.28 \%$ & -0.56 & 0.92 & 0.11 & 0.00 & 0.96 & $-0.77 \%$ & -1.56 & 0.93 & 0.12 & 0.00 & 0.04 & 0.97 \\
\hline D6 & $-0.55 \%$ & -1.01 & 0.92 & 0.02 & 0.04 & 0.95 & $-0.79 \%$ & -1.43 & 0.92 & 0.03 & 0.04 & 0.02 & 0.95 \\
\hline D7 & $-0.83 \%$ & -1.96 & 0.92 & -0.02 & 0.05 & 0.97 & $-0.92 \%$ & -2.11 & 0.92 & -0.02 & 0.05 & 0.01 & 0.97 \\
\hline D8 & $-0.76 \%$ & -1.94 & 0.89 & -0.06 & 0.05 & 0.97 & $-0.78 \%$ & -1.95 & 0.90 & -0.06 & 0.05 & 0.00 & 0.97 \\
\hline D9 & $-1.07 \%$ & -2.75 & 0.90 & -0.09 & 0.03 & 0.97 & $-1.08 \%$ & -2.71 & 0.90 & -0.09 & 0.03 & 0.00 & 0.97 \\
\hline D10 & $-0.94 \%$ & -1.30 & 0.92 & -0.17 & -0.01 & 0.92 & $-0.77 \%$ & -1.03 & 0.92 & -0.17 & -0.02 & -0.01 & 0.92 \\
\hline
\end{tabular}


Table III. Multiple-factor regressions (Continued)

\begin{tabular}{|c|c|c|c|c|c|c|c|c|c|c|c|c|c|}
\hline & \multicolumn{6}{|c|}{ Fama and French 3FM } & \multicolumn{7}{|c|}{ Carhart 4FM } \\
\hline & Alpha & Alpha-t & RMRF & SMB & HML & Rsq & Alpha & Alpha-t & RMRF & SMB & HML & WML & Rsq \\
\hline \multicolumn{14}{|c|}{ Sorts on value beta } \\
\hline D1 & $-1.70 \%$ & -2.09 & 0.86 & 0.22 & 0.44 & 0.88 & $-1.72 \%$ & -2.06 & 0.86 & 0.22 & 0.44 & 0.00 & 0.88 \\
\hline D2 & $-0.79 \%$ & -1.16 & 0.87 & 0.12 & 0.31 & 0.91 & $-0.91 \%$ & -1.31 & 0.87 & 0.12 & 0.31 & 0.01 & 0.91 \\
\hline D3 & $-0.95 \%$ & -1.49 & 0.89 & 0.07 & 0.22 & 0.93 & $-0.92 \%$ & -1.41 & 0.89 & 0.07 & 0.22 & 0.00 & 0.93 \\
\hline D4 & $-1.37 \%$ & -2.71 & 0.90 & 0.10 & 0.14 & 0.96 & $-1.63 \%$ & -3.16 & 0.91 & 0.11 & 0.15 & 0.02 & 0.96 \\
\hline D5 & $-1.12 \%$ & -2.52 & 0.93 & 0.10 & 0.05 & 0.97 & $-1.46 \%$ & -3.25 & 0.93 & 0.11 & 0.06 & 0.02 & 0.97 \\
\hline D6 & $-0.78 \%$ & -1.58 & 0.95 & 0.08 & -0.03 & 0.96 & $-1.27 \%$ & -2.55 & 0.95 & 0.09 & -0.02 & 0.04 & 0.97 \\
\hline D7 & $-0.75 \%$ & -1.52 & 0.96 & 0.15 & -0.10 & 0.97 & $-1.57 \%$ & -3.30 & 0.97 & 0.16 & -0.08 & 0.06 & 0.97 \\
\hline D8 & $-0.37 \%$ & -0.70 & 0.96 & 0.18 & -0.23 & 0.97 & $-1.20 \%$ & -2.37 & 0.97 & 0.20 & -0.22 & 0.06 & 0.97 \\
\hline D9 & $0.22 \%$ & 0.36 & 0.99 & 0.23 & -0.34 & 0.96 & $-0.71 \%$ & -1.20 & 1.00 & 0.25 & -0.33 & 0.07 & 0.97 \\
\hline D10 & $1.95 \%$ & 1.95 & 1.06 & 0.39 & -0.55 & 0.93 & $0.87 \%$ & 0.87 & 1.07 & 0.41 & -0.54 & 0.08 & 0.94 \\
\hline \multicolumn{14}{|c|}{ Sorts on past return } \\
\hline D1 & $5.58 \%$ & 3.94 & 0.86 & 0.57 & -0.17 & 0.80 & $0.89 \%$ & 0.82 & 0.90 & 0.65 & -0.10 & 0.34 & 0.89 \\
\hline D2 & $3.13 \%$ & 3.49 & 0.90 & 0.38 & -0.06 & 0.90 & $0.37 \%$ & 0.51 & 0.93 & 0.43 & -0.02 & 0.20 & 0.94 \\
\hline D3 & $1.63 \%$ & 2.53 & 0.91 & 0.22 & -0.03 & 0.94 & $-0.13 \%$ & -0.24 & 0.93 & 0.25 & -0.01 & 0.13 & 0.96 \\
\hline D4 & $0.10 \%$ & 0.21 & 0.93 & 0.15 & 0.00 & 0.96 & $-1.08 \%$ & -2.42 & 0.94 & 0.17 & 0.02 & 0.09 & 0.97 \\
\hline D5 & $-1.04 \%$ & -2.19 & 0.95 & 0.11 & 0.03 & 0.96 & $-1.66 \%$ & -3.53 & 0.95 & 0.12 & 0.04 & 0.04 & 0.97 \\
\hline D6 & $-1.07 \%$ & -2.15 & 0.94 & 0.07 & 0.02 & 0.96 & $-1.07 \%$ & -2.11 & 0.94 & 0.07 & 0.02 & 0.00 & 0.96 \\
\hline D7 & $-1.95 \%$ & -3.75 & 0.94 & 0.06 & 0.03 & 0.96 & $-1.58 \%$ & -2.99 & 0.94 & 0.06 & 0.03 & -0.03 & 0.96 \\
\hline D8 & $-3.22 \%$ & -4.67 & 0.96 & 0.09 & 0.04 & 0.93 & $-2.18 \%$ & -3.23 & 0.95 & 0.07 & 0.03 & -0.08 & 0.93 \\
\hline D9 & $-4.24 \%$ & -4.93 & 0.96 & 0.10 & 0.04 & 0.89 & $-2.66 \%$ & -3.24 & 0.95 & 0.07 & 0.02 & -0.12 & 0.91 \\
\hline D10 & $-6.51 \%$ & -4.64 & 0.94 & 0.13 & 0.02 & 0.75 & $-2.84 \%$ & -2.31 & 0.90 & 0.06 & -0.03 & -0.27 & 0.82 \\
\hline
\end{tabular}




\section{Table IV. Multivariate test results for zero alphas}

We obtain our data on returns of mutual funds from the 2003 CRSP Mutual Fund Survivor-Bias-Free Database. Our sample comprises 7,852 U.S. equity funds over the period 1963-2003. We sort funds into 10 , 20, and 30 quantile portfolios based on the market beta, size beta, value beta, and past returns of their stock holdings. For the resulting style portfolios, we run Fama and French 3FM and Carhart 4FM regressions, and test whether the estimated alphas are jointly equal to zero. The table lists the results of pooled timeseries-cross-sectional tests in the spirit of Gibbons et al. (1989). p-values below the significance level of $10 \%$ appear in boldface.

\begin{tabular}{lllllllll}
\hline \hline & & & & & & & & \\
\multicolumn{1}{c}{ Fama and French 3FM } & \multicolumn{7}{c}{ Carhart 4FM } \\
& Chi & p-value & GRS & p-value & Chi & p-value & GRS & p-value \\
\hline$N=10$ & & & & & & & & \\
market & 10.87 & 0.37 & 1.06 & 0.39 & 13.87 & 0.18 & 1.34 & 0.20 \\
size & 13.10 & 0.22 & 1.27 & 0.24 & 11.26 & 0.34 & 1.09 & 0.37 \\
value & 20.07 & $\mathbf{0 . 0 3}$ & 1.95 & $\mathbf{0 . 0 4}$ & 27.09 & $\mathbf{0 . 0 0}$ & 2.63 & $\mathbf{0 . 0 1}$ \\
return & 32.19 & $\mathbf{0 . 0 0}$ & 3.13 & $\mathbf{0 . 0 0}$ & 19.32 & $\mathbf{0 . 0 4}$ & 1.87 & $\mathbf{0 . 0 5}$ \\
& & & & & & & & \\
\hline$N=20$ & & & & & & & & \\
market & 25.28 & 0.19 & 1.20 & 0.25 & 31.09 & 0.05 & 1.47 & 0.09 \\
size & 39.06 & $\mathbf{0 . 0 1}$ & 1.85 & $\mathbf{0 . 0 1}$ & 34.87 & $\mathbf{0 . 0 2}$ & 1.65 & 0.04 \\
value & 43.11 & $\mathbf{0 . 0 0}$ & 2.05 & $\mathbf{0 . 0 1}$ & 57.85 & $\mathbf{0 . 0 0}$ & 2.74 & $\mathbf{0 . 0 0}$ \\
return & 44.29 & $\mathbf{0 . 0 0}$ & 2.10 & $\mathbf{0 . 0 0}$ & 30.37 & $\mathbf{0 . 0 6}$ & 1.44 & $\mathbf{0 . 1 0}$ \\
& & & & & & & & \\
\hline$N=30$ & & & & & & & & \\
market & 27.66 & 0.59 & 0.86 & 0.68 & 35.10 & 0.24 & 1.08 & 0.35 \\
size & 41.23 & $\mathbf{0 . 0 8}$ & 1.27 & 0.16 & 37.57 & 0.16 & 1.16 & 0.26 \\
value & 46.23 & $\mathbf{0 . 0 3}$ & 1.43 & $\mathbf{0 . 0 7}$ & 51.07 & $\mathbf{0 . 0 1}$ & 1.58 & $\mathbf{0 . 0 3}$ \\
return & 47.72 & $\mathbf{0 . 0 2}$ & 1.48 & $\mathbf{0 . 0 5}$ & 33.84 & 0.29 & 1.04 & 0.41 \\
& & & & & & & & \\
\hline \hline
\end{tabular}




\section{Table V. Robustness to time-varying market betas}

We obtain our data on returns of mutual funds from the 2003 CRSP Mutual Fund Survivor-Bias-Free Database. Our sample comprises 7,852 U.S. equity funds over the period 1963-2003. We sort funds into 10 quantile portfolios based on the market beta, size beta, value beta, and past returns of their stock holdings. For the resulting style portfolios, we run conditional CAPM, Fama and French 3FM, and Carhart 4FM regressions, and test whether the estimated alphas are jointly equal to zero. We use the following information variables: the lagged level of the one-month Treasury bill yield, the lagged dividend yield of the CRSP valueweighted market index, a lagged measure of the slope of the term structure, a lagged default spread in the corporate bond market, and a January dummy. The table lists the results of pooled time-series-cross-sectional tests in the spirit of Gibbons et al. (1989). All values are annualized. p-values below the significance level of $10 \%$ appear in boldface.

\begin{tabular}{|c|c|c|c|c|c|c|c|c|c|c|c|c|c|c|}
\hline & D1 & D2 & D3 & D4 & D5 & D6 & D7 & D8 & D9 & D10 & Chi & p-value & GRS & p-value \\
\hline \multicolumn{15}{|c|}{ Conditional CAPM } \\
\hline market & -0.68 & -0.23 & -0.59 & -0.47 & -0.52 & -0.67 & -0.17 & -0.14 & -0.16 & -0.04 & 5.52 & 0.85 & 0.53 & 0.87 \\
\hline size & -0.08 & 0.42 & 0.26 & 0.18 & -0.21 & -0.41 & -0.72 & -0.74 & -1.21 & -1.25 & 14.11 & 0.17 & 1.36 & 0.20 \\
\hline value & 0.86 & 1.08 & 0.20 & -0.52 & -0.76 & -0.88 & -1.06 & -1.26 & -1.19 & -0.23 & 20.92 & 0.02 & 2.02 & 0.03 \\
\hline return & 5.87 & 3.40 & 1.82 & 0.26 & -0.80 & -0.97 & -1.75 & -2.97 & -3.89 & -6.16 & 29.22 & 0.00 & 2.82 & 0.00 \\
\hline \multicolumn{15}{|c|}{ Conditional Fama and French 3FM } \\
\hline market & 0.31 & 0.31 & -0.22 & -0.25 & -0.55 & -0.90 & -0.78 & -0.93 & -1.24 & -1.45 & 10.86 & 0.37 & 1.04 & 0.41 \\
\hline size & -0.87 & -0.15 & -0.06 & 0.02 & -0.32 & -0.55 & -0.87 & -0.83 & -1.16 & -0.95 & 16.52 & 0.09 & 1.59 & 0.11 \\
\hline value & -1.68 & -0.66 & -0.95 & -1.37 & -1.13 & -0.79 & -0.72 & -0.35 & 0.16 & 1.80 & 20.63 & 0.02 & 1.98 & 0.03 \\
\hline return & 5.86 & 3.17 & 1.66 & 0.07 & -1.07 & -1.15 & -1.99 & -3.34 & -4.31 & -6.65 & 33.68 & 0.00 & 3.23 & 0.00 \\
\hline \multicolumn{15}{|c|}{ Conditional Carhart 4FM } \\
\hline market & -1.23 & -1.15 & -1.20 & -0.68 & -0.73 & -0.75 & -0.70 & -0.79 & -1.27 & -1.94 & 13.78 & 0.18 & 1.32 & 0.22 \\
\hline size & -2.06 & -1.41 & -1.10 & -0.79 & -0.79 & -0.61 & -0.78 & -0.85 & -1.23 & -0.85 & 15.83 & 0.10 & 1.52 & 0.13 \\
\hline value & -1.61 & -0.47 & -0.67 & -1.45 & -1.40 & -1.17 & -1.48 & -1.32 & -1.06 & 0.17 & 26.59 & 0.00 & 2.55 & 0.01 \\
\hline return & 0.57 & 0.03 & -0.26 & -1.17 & -1.58 & -1.05 & -1.46 & -2.06 & -2.40 & -2.60 & 17.89 & 0.06 & 1.71 & 0.08 \\
\hline
\end{tabular}




\section{Table VI. Robustness to alternative cut-off points to compute factor premiums (1)}

We obtain our data on returns of mutual funds from the 2003 CRSP Mutual Fund Survivor-Bias-Free Database. Our sample comprises 7,852 U.S. equity funds over the period 1963-2003. We sort funds into 10 quantile portfolios based on the market beta, size beta, value beta, and past returns of their stock holdings. The table lists the correlations between the decile portfolios of funds for sorts on value beta and past return, and decile portfolios of stocks for sorts on book-to-market-equity and past return. The strongest correlations for the quantile portfolios of funds appear in boldface.

\begin{tabular}{|c|c|c|c|c|c|c|c|c|c|c|}
\hline & D1 & D2 & D3 & D4 & D5 & D6 & D7 & D8 & D9 & D10 \\
\hline \multicolumn{11}{|c|}{ Sorts on value beta } \\
\hline B2M1 & 0.90 & 0.93 & 0.93 & 0.92 & 0.92 & 0.90 & 0.87 & 0.84 & 0.80 & 0.73 \\
\hline B2M2 & 0.87 & 0.92 & 0.93 & 0.95 & 0.96 & 0.95 & 0.95 & 0.93 & 0.90 & 0.85 \\
\hline B2M3 & 0.83 & 0.89 & 0.91 & 0.93 & 0.95 & 0.95 & 0.95 & 0.94 & 0.92 & 0.88 \\
\hline B2M4 & 0.78 & 0.84 & 0.87 & 0.90 & 0.91 & 0.92 & 0.93 & 0.93 & 0.91 & 0.87 \\
\hline B2M5 & 0.74 & 0.80 & 0.83 & 0.86 & 0.88 & 0.90 & 0.91 & 0.91 & 0.91 & 0.88 \\
\hline B2M6 & 0.76 & 0.82 & 0.84 & 0.87 & 0.89 & 0.90 & 0.92 & 0.92 & 0.91 & 0.88 \\
\hline B2M7 & 0.70 & 0.76 & 0.79 & 0.82 & 0.84 & 0.87 & 0.88 & 0.89 & 0.90 & 0.89 \\
\hline B2M8 & 0.70 & 0.76 & 0.79 & 0.83 & 0.85 & 0.87 & 0.89 & 0.90 & 0.91 & 0.91 \\
\hline B2M9 & 0.71 & 0.76 & 0.79 & 0.83 & 0.84 & 0.86 & 0.88 & 0.88 & 0.89 & 0.89 \\
\hline B2M10 & 0.67 & 0.72 & 0.75 & 0.79 & 0.80 & 0.82 & 0.84 & 0.84 & 0.85 & 0.86 \\
\hline \multicolumn{11}{|c|}{ Sorts on past return } \\
\hline MOM1 & 0.93 & 0.94 & 0.93 & 0.90 & 0.87 & 0.84 & 0.83 & 0.79 & 0.76 & 0.64 \\
\hline MOM2 & 0.81 & 0.88 & 0.91 & 0.92 & 0.91 & 0.89 & 0.88 & 0.86 & 0.83 & 0.70 \\
\hline MOM3 & 0.78 & 0.86 & 0.90 & 0.92 & 0.91 & 0.90 & 0.89 & 0.87 & 0.84 & 0.73 \\
\hline MOM4 & 0.71 & 0.81 & 0.87 & 0.89 & 0.91 & 0.90 & 0.90 & 0.88 & 0.86 & 0.76 \\
\hline MOM5 & 0.69 & 0.80 & 0.86 & 0.89 & 0.91 & 0.92 & 0.92 & 0.91 & 0.90 & 0.82 \\
\hline MOM6 & 0.65 & 0.77 & 0.84 & 0.88 & 0.90 & 0.91 & 0.91 & 0.91 & 0.90 & 0.84 \\
\hline MOM7 & 0.59 & 0.72 & 0.79 & 0.84 & 0.87 & 0.89 & 0.90 & 0.91 & 0.90 & 0.87 \\
\hline MOM8 & 0.54 & 0.67 & 0.75 & 0.80 & 0.83 & 0.86 & 0.87 & 0.88 & 0.89 & 0.87 \\
\hline MOM9 & 0.56 & 0.68 & 0.74 & 0.79 & 0.82 & 0.85 & 0.86 & 0.88 & 0.89 & 0.89 \\
\hline MOM10 & 0.58 & 0.69 & 0.73 & 0.76 & 0.78 & 0.81 & 0.83 & 0.84 & 0.86 & 0.87 \\
\hline
\end{tabular}




\section{Table VII. Robustness to alternative cut-off points to compute factor premiums (2)}

We obtain our data on returns of mutual funds from the 2003 CRSP Mutual Fund Survivor-Bias-Free Database. Our sample comprises 7,852 U.S. equity funds over the period 1963-2003. We sort funds into 10 quantile portfolios based on the market beta, size beta, value beta, and past returns of their stock holdings. For the resulting style portfolios, we run Carhart 4FM regressions with a more extreme momentum factor $\mathrm{WML}^{*}$ using cutoff points corresponding to the $90^{\text {th }}$ and $10^{\text {th }}$ percentiles of stocks sorted on past return. The table lists the portfolios' post-ranking returns, Sharpe ratios, Fama and French 3FM and Carhart 4FM parameter estimates, and R-squared values. All values are annualized.

\begin{tabular}{|c|c|c|c|c|c|c|c|}
\hline & Alpha & Alpha-t & RMRF & SMB & HML & WML* & Rsq \\
\hline \multicolumn{8}{|c|}{ Sorts on past return } \\
\hline D1 & $0.99 \%$ & 0.86 & 0.89 & 0.66 & -0.09 & 0.26 & 0.88 \\
\hline D2 & $0.45 \%$ & 0.59 & 0.92 & 0.43 & -0.02 & 0.15 & 0.93 \\
\hline D3 & $-0.13 \%$ & -0.22 & 0.92 & 0.25 & 0.00 & 0.10 & 0.95 \\
\hline D4 & $-1.13 \%$ & -2.52 & 0.94 & 0.18 & 0.03 & 0.07 & 0.97 \\
\hline D5 & $-1.75 \%$ & -3.72 & 0.95 & 0.12 & 0.05 & 0.04 & 0.97 \\
\hline D6 & $-1.23 \%$ & -2.42 & 0.95 & 0.07 & 0.03 & 0.01 & 0.96 \\
\hline D7 & $-1.75 \%$ & -3.28 & 0.94 & 0.06 & 0.03 & -0.01 & 0.96 \\
\hline D8 & $-2.45 \%$ & -3.53 & 0.96 & 0.07 & 0.03 & -0.04 & 0.93 \\
\hline D9 & $-2.99 \%$ & -3.51 & 0.95 & 0.07 & 0.02 & -0.07 & 0.90 \\
\hline D10 & $-3.28 \%$ & -2.53 & 0.92 & 0.06 & -0.03 & -0.18 & 0.80 \\
\hline
\end{tabular}




\section{Table VIII. Robustness to differences in fund expenses}

We obtain our data on returns of mutual funds from the 2003 CRSP Mutual Fund Survivor-Bias-Free Database. Our sample comprises 7,852 U.S. equity funds over the period 1963-2003. We sort funds into 10 quantile portfolios based on the market beta, size beta, value beta, and past returns of their stock holdings. We then examine the pre-expense returns of the style portfolios. We obtain pre-expense returns for every month by taking the sum of a fund's monthly return and one twelfth of the yearly expense ratio reported by the fund in the respective year. For the resulting style portfolios' pre-expense returns, we run CAPM, Fama and French 3FM and Carhart 4FM regressions. The table lists the portfolios' expenses, Sharpe ratios, CAPM, Fama and French 3FM and Carhart 4FM alphas. All values are annualized.

\begin{tabular}{|c|c|c|c|c|c|c|c|}
\hline & \multicolumn{3}{|c|}{ CAPM } & \multicolumn{2}{|c|}{ Fama-French 3FM } & \multicolumn{2}{|c|}{ Carhart 4FM } \\
\hline & Expenses & Alpha & Alpha-t & Alpha & Alpha-t & Alpha & Alpha-t \\
\hline \multicolumn{8}{|c|}{ Sorts on market beta } \\
\hline D1 & $1.38 \%$ & $-0.28 \%$ & -0.23 & $-0.76 \%$ & -0.69 & $-0.63 \%$ & -0.56 \\
\hline $\mathrm{D} 2$ & $1.21 \%$ & $0.76 \%$ & 0.93 & $0.67 \%$ & 0.97 & $0.23 \%$ & 0.32 \\
\hline D3 & $1.13 \%$ & $0.51 \%$ & 0.78 & $0.46 \%$ & 0.83 & $-0.10 \%$ & -0.17 \\
\hline D4 & $1.07 \%$ & $0.87 \%$ & 1.37 & $0.67 \%$ & 1.13 & $0.03 \%$ & 0.05 \\
\hline D5 & $1.03 \%$ & $1.25 \%$ & 2.23 & $1.13 \%$ & 2.06 & $0.66 \%$ & 1.19 \\
\hline D6 & $1.00 \%$ & $0.82 \%$ & 1.78 & $0.67 \%$ & 1.54 & $0.27 \%$ & 0.62 \\
\hline D7 & $1.04 \%$ & $0.88 \%$ & 1.96 & $0.88 \%$ & 2.09 & $0.44 \%$ & 1.04 \\
\hline D8 & $1.09 \%$ & $0.55 \%$ & 1.03 & $0.48 \%$ & 1.00 & $-0.22 \%$ & -0.47 \\
\hline D9 & $1.14 \%$ & $1.38 \%$ & 2.49 & $0.89 \%$ & 1.78 & $0.36 \%$ & 0.72 \\
\hline D10 & $1.18 \%$ & $1.67 \%$ & 2.01 & $0.57 \%$ & 0.73 & $-0.22 \%$ & -0.28 \\
\hline \multicolumn{8}{|c|}{ Sorts on size beta } \\
\hline D1 & $1.43 \%$ & $1.44 \%$ & 0.89 & $0.58 \%$ & 0.61 & $-0.46 \%$ & -0.48 \\
\hline $\mathrm{D} 2$ & $1.26 \%$ & $1.65 \%$ & 1.31 & $0.96 \%$ & 1.13 & $-0.22 \%$ & -0.27 \\
\hline D3 & $1.22 \%$ & $1.61 \%$ & 1.73 & $1.18 \%$ & 1.75 & $0.15 \%$ & 0.23 \\
\hline D4 & $1.18 \%$ & $1.23 \%$ & 1.75 & $1.07 \%$ & 1.89 & $0.22 \%$ & 0.40 \\
\hline D5 & $1.13 \%$ & $1.04 \%$ & 1.99 & $0.85 \%$ & 1.73 & $0.36 \%$ & 0.72 \\
\hline D6 & $1.06 \%$ & $0.78 \%$ & 1.48 & $0.51 \%$ & 0.94 & $0.27 \%$ & 0.48 \\
\hline D7 & $1.04 \%$ & $0.50 \%$ & 1.19 & $0.21 \%$ & 0.49 & $0.12 \%$ & 0.28 \\
\hline D8 & $1.01 \%$ & $0.46 \%$ & 1.13 & $0.25 \%$ & 0.65 & $0.23 \%$ & 0.57 \\
\hline D9 & $0.96 \%$ & $-0.11 \%$ & -0.27 & $-0.11 \%$ & -0.29 & $-0.12 \%$ & -0.30 \\
\hline D10 & $0.99 \%$ & $-0.36 \%$ & -0.48 & $0.04 \%$ & 0.06 & $0.22 \%$ & 0.30 \\
\hline
\end{tabular}


Table VIII. Robustness to differences in fund expenses (Continued)

\begin{tabular}{|c|c|c|c|c|c|c|c|}
\hline & \multicolumn{3}{|c|}{ A. CAPM } & \multicolumn{2}{|c|}{ B. Fama-French 3FM } & \multicolumn{2}{|c|}{ C. Carhart 4FM } \\
\hline & Expenses & Alpha & Alpha-t & Alpha & Alpha-t & Alpha & Alpha-t \\
\hline \multicolumn{8}{|c|}{ Sorts on value beta } \\
\hline D1 & $1.22 \%$ & $2.79 \%$ & 2.59 & $-0.48 \%$ & -0.59 & $-0.50 \%$ & -0.59 \\
\hline D2 & $1.11 \%$ & $2.55 \%$ & 3.09 & $0.32 \%$ & 0.47 & $0.20 \%$ & 0.29 \\
\hline D3 & $1.09 \%$ & $1.71 \%$ & 2.41 & $0.15 \%$ & 0.23 & $0.17 \%$ & 0.27 \\
\hline D4 & $1.08 \%$ & $0.83 \%$ & 1.48 & $-0.29 \%$ & -0.57 & $-0.55 \%$ & -1.06 \\
\hline D5 & $1.08 \%$ & $0.49 \%$ & 1.05 & $-0.05 \%$ & -0.11 & $-0.39 \%$ & -0.86 \\
\hline D6 & $1.05 \%$ & $0.23 \%$ & 0.45 & $0.27 \%$ & 0.53 & $-0.22 \%$ & -0.45 \\
\hline D7 & $1.10 \%$ & $0.02 \%$ & 0.03 & $0.35 \%$ & 0.70 & $-0.47 \%$ & -0.99 \\
\hline D8 & $1.13 \%$ & $-0.37 \%$ & -0.51 & $0.77 \%$ & 1.47 & $-0.06 \%$ & -0.13 \\
\hline D9 & $1.14 \%$ & $-0.38 \%$ & -0.41 & $1.36 \%$ & 2.22 & $0.43 \%$ & 0.72 \\
\hline D10 & $1.27 \%$ & $0.42 \%$ & 0.27 & $3.23 \%$ & 3.23 & $2.15 \%$ & 2.15 \\
\hline \multicolumn{8}{|c|}{ Sorts on past return } \\
\hline D1 & $1.29 \%$ & $6.95 \%$ & 4.00 & $6.87 \%$ & 4.85 & $2.19 \%$ & 2.00 \\
\hline D2 & $1.15 \%$ & $4.66 \%$ & 4.21 & $4.28 \%$ & 4.78 & $1.52 \%$ & 2.09 \\
\hline D3 & $1.10 \%$ & $2.96 \%$ & 4.01 & $2.73 \%$ & 4.24 & $0.96 \%$ & 1.74 \\
\hline D4 & $1.08 \%$ & $1.54 \%$ & 2.79 & $1.19 \%$ & 2.40 & $0.00 \%$ & 0.01 \\
\hline D5 & $1.07 \%$ & $0.48 \%$ & 0.96 & $0.03 \%$ & 0.05 & $-0.59 \%$ & -1.26 \\
\hline D6 & $1.07 \%$ & $0.30 \%$ & 0.61 & $0.00 \%$ & 0.01 & $0.00 \%$ & 0.00 \\
\hline D7 & $1.10 \%$ & $-0.49 \%$ & -0.95 & $-0.84 \%$ & -1.62 & $-0.47 \%$ & -0.90 \\
\hline D8 & $1.14 \%$ & $-1.60 \%$ & -2.32 & $-2.08 \%$ & -3.02 & $-1.04 \%$ & -1.54 \\
\hline D9 & $1.20 \%$ & $-2.57 \%$ & -3.01 & $-3.04 \%$ & -3.54 & $-1.46 \%$ & -1.77 \\
\hline D10 & $1.39 \%$ & $-4.70 \%$ & -3.40 & $-5.12 \%$ & -3.65 & $-1.44 \%$ & -1.17 \\
\hline
\end{tabular}




\section{Table IX. Results using factors proxies based on fund returns}

We obtain our data on returns of mutual funds from the 2003 CRSP Mutual Fund Survivor-Bias-Free Database. Our sample comprises 7,852 U.S. equity funds over the period 1963-2003. We sort funds into 10 quantile portfolios based on the market beta, size beta, value beta, and past returns of their stock holdings. For the resulting style portfolios, we run three- and four-factor model regressions using factor proxies based on fund returns, and test whether the estimated alphas are jointly equal to zero. The table lists the results of pooled time-series-cross-sectional tests in the spirit of Gibbons et al. (1989). All values are annualized. pvalues below the significance level of $10 \%$ appear in boldface.

\begin{tabular}{|c|c|c|c|c|c|c|c|c|c|c|c|c|c|c|}
\hline & D1 & D2 & D3 & D4 & D5 & D6 & D7 & D8 & D9 & D10 & Chi & p-value & GRS & p-value \\
\hline \multicolumn{15}{|c|}{ 3FM results with top minus bottom 50 percent factors } \\
\hline market & -0.13 & 0.32 & -0.16 & 0.17 & 0.01 & -0.08 & 0.32 & 0.12 & -0.09 & -0.41 & 4.42 & 0.93 & 0.43 & 0.93 \\
\hline size & -0.75 & -0.08 & 0.33 & 0.32 & 0.31 & 0.12 & -0.01 & 0.04 & -0.23 & 0.00 & 6.76 & 0.75 & 0.66 & 0.76 \\
\hline value & 0.09 & 0.54 & 0.16 & -0.39 & -0.39 & -0.31 & -0.38 & -0.38 & -0.09 & 1.15 & 10.99 & 0.36 & 1.07 & 0.39 \\
\hline return & 5.94 & 3.59 & 2.15 & 0.63 & -0.43 & -0.55 & -1.45 & -2.68 & -3.88 & -6.05 & 37.01 & 0.00 & 3.60 & 0.00 \\
\hline \multicolumn{15}{|c|}{ 4FM results with top minus bottom 50 percent factors } \\
\hline market & 0.04 & 0.14 & -0.42 & 0.24 & -0.07 & 0.14 & 0.60 & 0.25 & -0.10 & -0.76 & 8.51 & 0.58 & 0.83 & 0.60 \\
\hline size & -0.41 & -0.21 & 0.23 & 0.14 & 0.39 & 0.16 & 0.11 & 0.08 & -0.32 & -0.12 & 6.99 & 0.73 & 0.68 & 0.75 \\
\hline value & 0.03 & 0.43 & 0.33 & -0.35 & -0.43 & -0.34 & -0.61 & -0.43 & 0.00 & 1.38 & 13.92 & 0.18 & 1.35 & 0.20 \\
\hline return & 0.23 & 0.22 & 0.03 & -0.47 & -0.73 & 0.09 & -0.12 & -0.23 & -0.47 & -0.02 & 12.17 & 0.27 & 1.18 & 0.30 \\
\hline
\end{tabular}


Table IX. Results using factors proxies based on fund returns (Continued)

\begin{tabular}{|c|c|c|c|c|c|c|c|c|c|c|c|c|c|c|}
\hline & D1 & D2 & D3 & D4 & D5 & D6 & D7 & D8 & D9 & D10 & Chi & p-value & GRS & p-value \\
\hline \multicolumn{15}{|c|}{$3 F M$ results with top minus bottom 33 percent factors } \\
\hline market & -0.04 & 0.38 & -0.15 & 0.17 & -0.04 & -0.11 & 0.29 & 0.09 & -0.12 & -0.40 & 4.82 & 0.90 & 0.47 & 0.91 \\
\hline size & -0.69 & -0.04 & 0.35 & 0.34 & 0.32 & 0.05 & -0.05 & 0.01 & -0.25 & 0.00 & 4.83 & 0.90 & 0.47 & 0.91 \\
\hline value & 0.05 & 0.50 & 0.10 & -0.38 & -0.39 & -0.35 & -0.40 & -0.36 & -0.05 & 1.27 & 12.21 & 0.27 & 1.19 & 0.30 \\
\hline return & 6.02 & 3.62 & 2.15 & 0.62 & -0.45 & -0.59 & -1.46 & -2.68 & -3.88 & -6.03 & 36.99 & 0.00 & 3.59 & 0.00 \\
\hline \multicolumn{15}{|c|}{ 4FM results with top minus bottom 33 percent factors } \\
\hline market & 0.03 & 0.13 & -0.43 & 0.25 & -0.12 & 0.15 & 0.62 & 0.27 & -0.10 & -0.75 & 8.80 & 0.55 & 0.85 & 0.58 \\
\hline size & -0.40 & -0.17 & 0.25 & 0.14 & 0.37 & 0.11 & 0.13 & 0.08 & -0.31 & -0.15 & 4.33 & 0.93 & 0.42 & 0.94 \\
\hline value & 0.00 & 0.41 & 0.30 & -0.30 & -0.39 & -0.37 & -0.66 & -0.42 & -0.01 & 1.43 & 14.25 & 0.16 & 1.38 & 0.19 \\
\hline return & -0.06 & 0.06 & -0.06 & -0.49 & -0.67 & 0.04 & -0.09 & -0.11 & -0.29 & 0.28 & 9.73 & 0.46 & 0.94 & 0.49 \\
\hline \multicolumn{15}{|c|}{ 3FM results with top minus bottom 20 percent factors } \\
\hline market & -0.10 & 0.34 & -0.19 & 0.11 & -0.04 & -0.15 & 0.30 & 0.13 & -0.04 & -0.30 & 4.41 & 0.93 & 0.43 & 0.93 \\
\hline size & -0.51 & 0.11 & 0.44 & 0.37 & 0.30 & 0.06 & -0.11 & -0.08 & -0.37 & -0.18 & 9.77 & 0.46 & 0.95 & 0.49 \\
\hline value & 0.28 & 0.67 & 0.25 & -0.33 & -0.39 & -0.40 & -0.47 & -0.50 & -0.20 & 1.08 & 14.01 & 0.17 & 1.36 & 0.20 \\
\hline return & 6.04 & 3.63 & 2.13 & 0.60 & -0.46 & -0.58 & -1.49 & -2.68 & -3.88 & -6.01 & 36.62 & 0.00 & 3.56 & 0.00 \\
\hline \multicolumn{15}{|c|}{ 4FM results with top minus bottom 20 percent factors } \\
\hline market & -0.30 & 0.16 & -0.51 & 0.00 & 0.11 & 0.02 & 0.52 & 0.42 & 0.09 & -0.47 & 6.80 & 0.74 & 0.66 & 0.76 \\
\hline size & -0.50 & 0.02 & 0.42 & 0.23 & 0.28 & 0.18 & -0.04 & 0.00 & -0.38 & -0.25 & 10.37 & 0.41 & 1.00 & 0.44 \\
\hline value & 0.19 & 0.56 & 0.59 & -0.19 & -0.28 & -0.35 & -0.70 & -0.48 & -0.22 & 0.92 & 13.03 & 0.22 & 1.26 & 0.25 \\
\hline return & 1.40 & 1.31 & 0.80 & -0.18 & -0.65 & -0.10 & -0.71 & -0.94 & -1.42 & -1.30 & 15.74 & 0.11 & 1.53 & 0.13 \\
\hline
\end{tabular}


Figure 1. Mutual funds' average excess returns and market betas

Panel A. Sorts on market beta

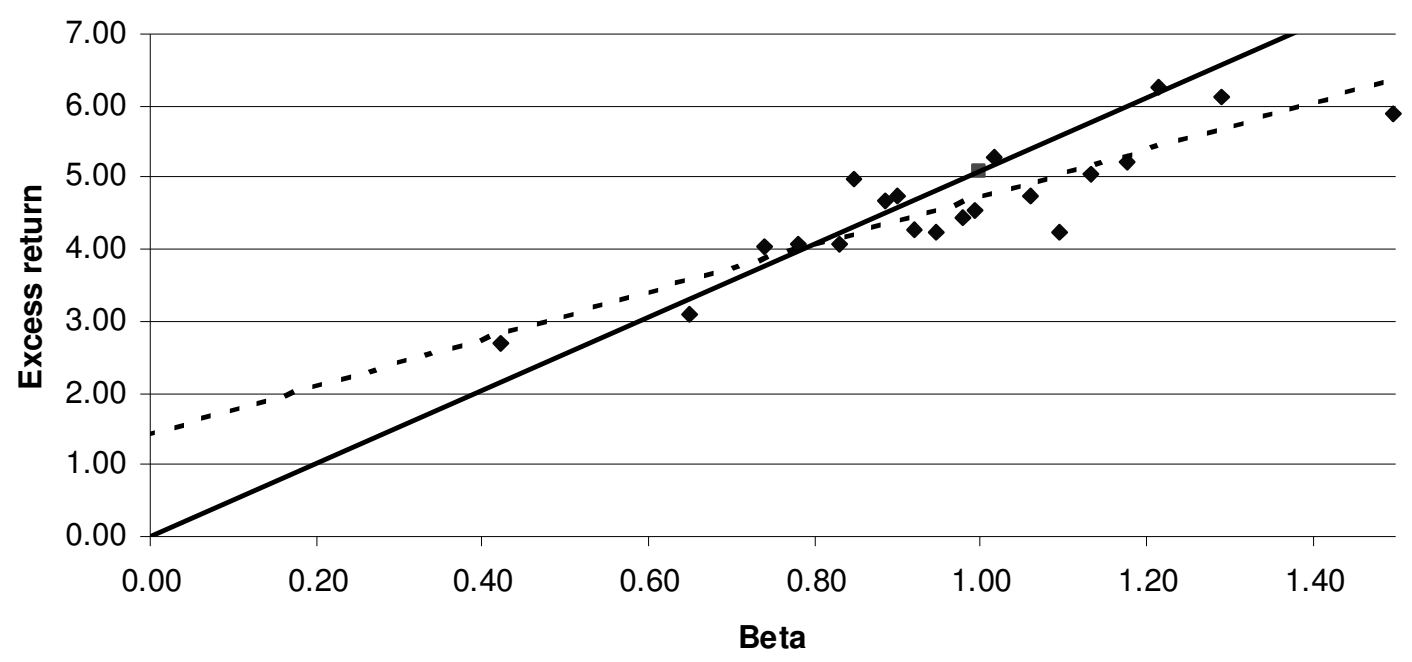

Panel B. Sorts on size beta

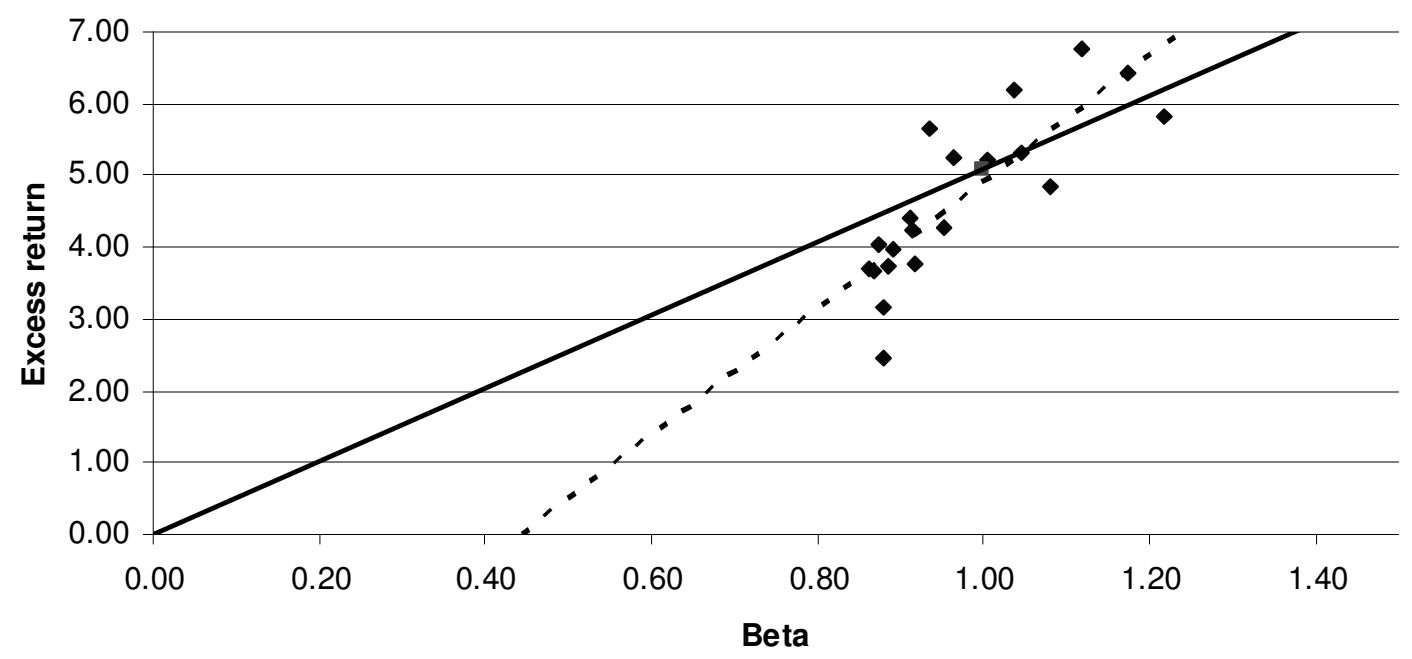


Figure 1. Mutual funds' average excess returns and market betas (Continued)

Panel C. Sorts on value beta

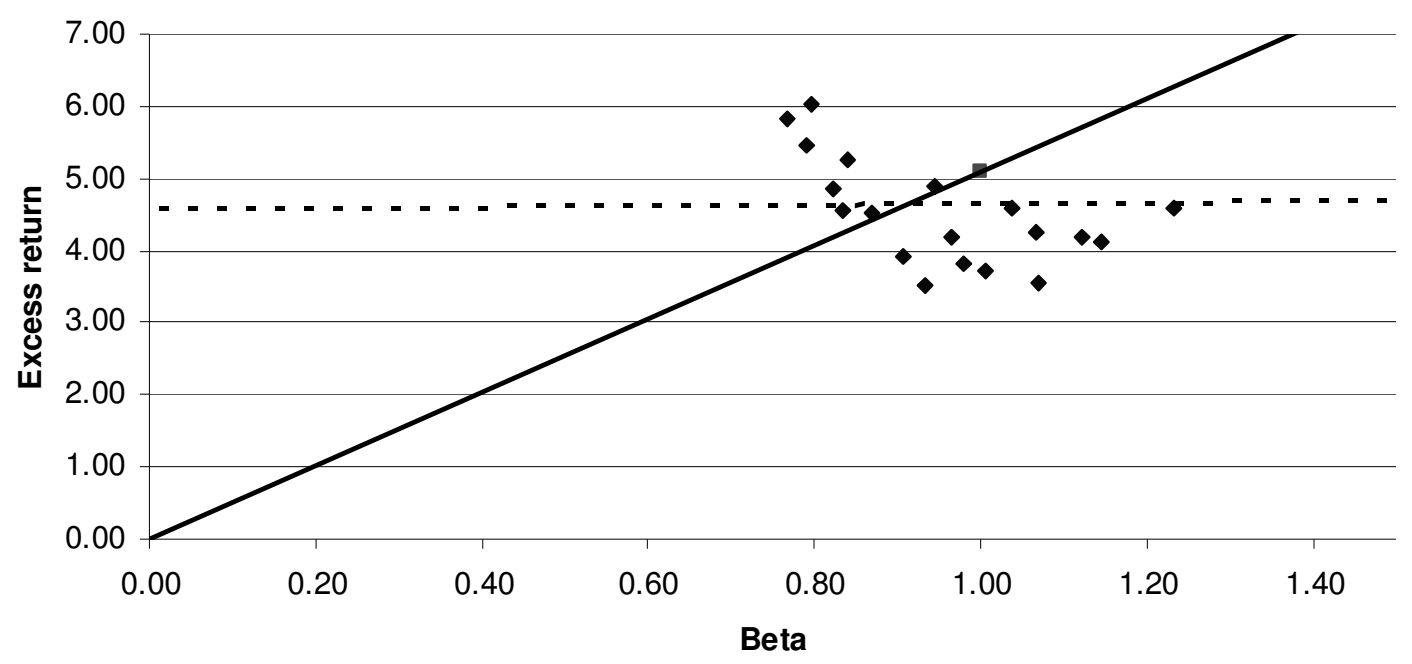

Panel D. Sorts on past return

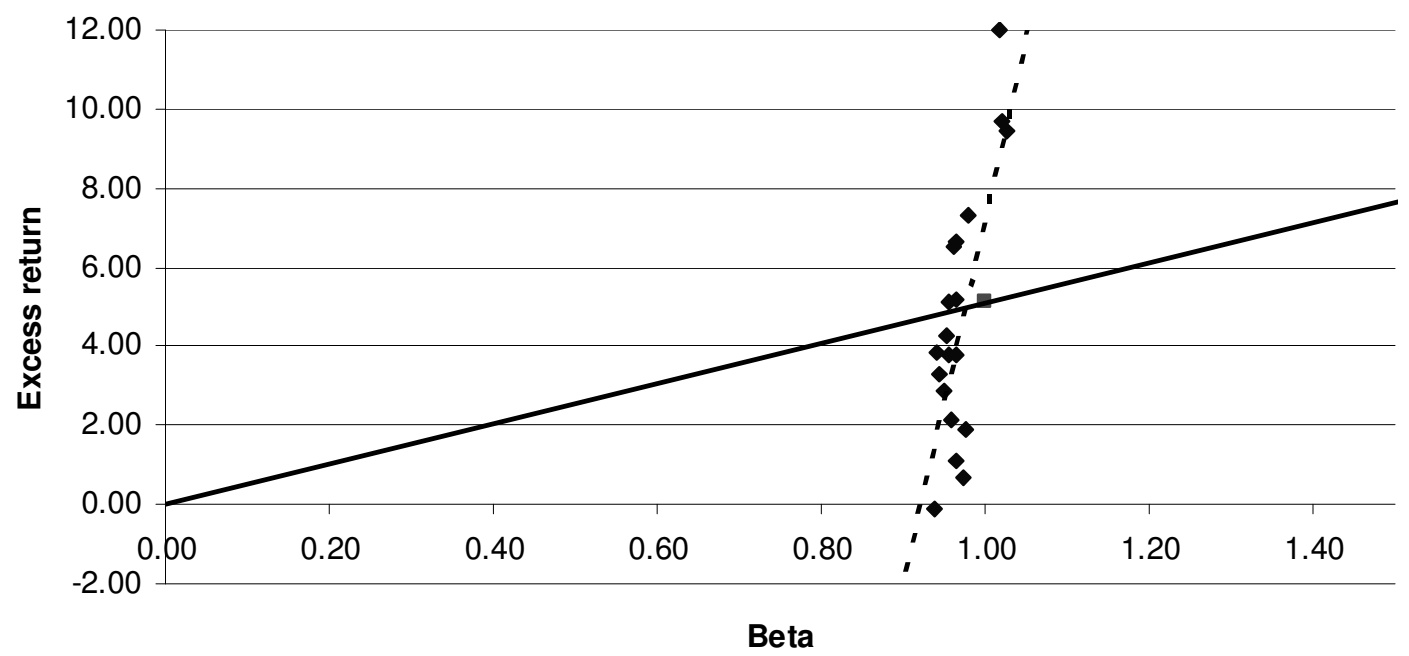

We obtain our data on returns of mutual funds from the 2003 CRSP Mutual Fund Survivor-Bias-Free Database. Our sample comprises 7,852 U.S. equity funds over the period 1963-2003. We sort funds into 20 quantile portfolios based on the market beta (Panel A), size beta (Panel B), value beta (Panel C), and past returns of their stock holdings (Panel D). For the resulting style portfolios, we compute average excess returns and plot these values on the portfolios' market betas that we estimate by using single-factor CAPM regressions. The solid line in the graphs shows the SML predicted by the CAPM, and the dashed line shows the empirical relation between expected excess return and market beta. All values are annualized. 
Figure 2. Single-factor CAPM alphas

Panel A. Sorts on market beta

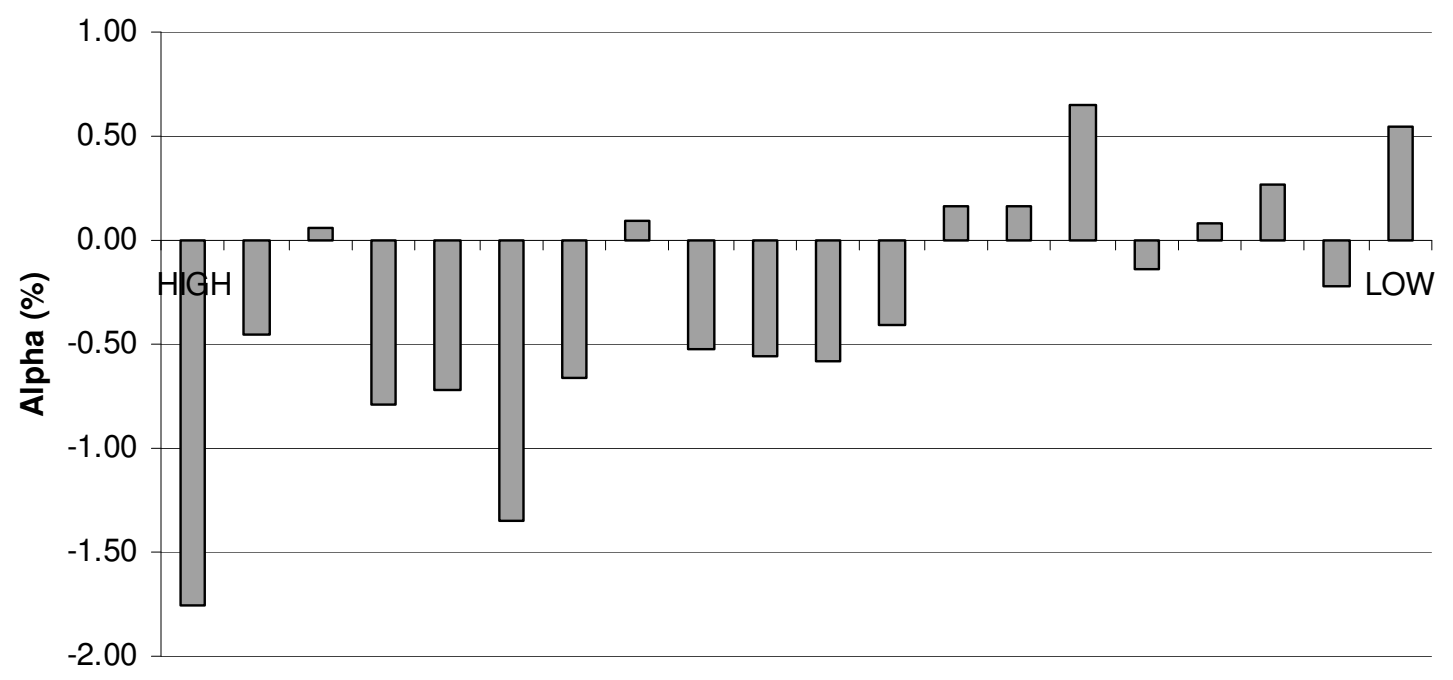

Panel B. Sorts on size beta

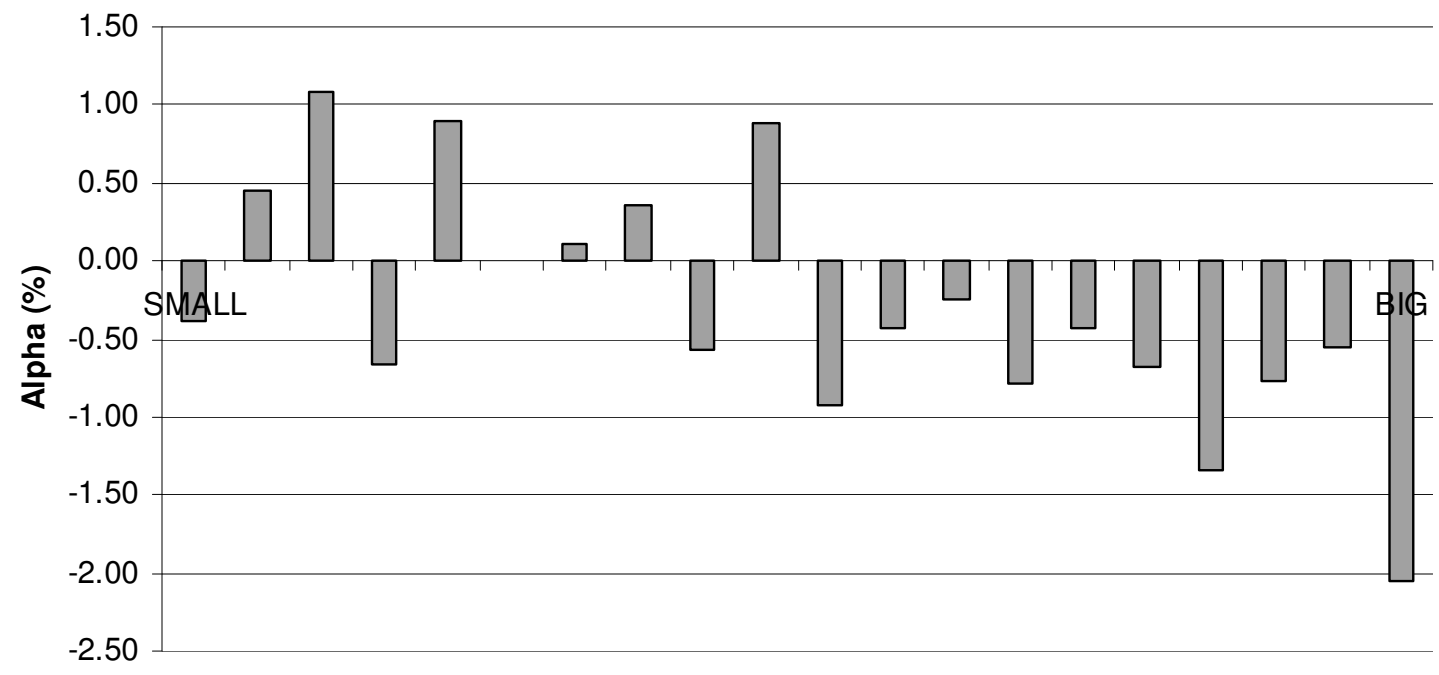


Figure 2. Single-factor CAPM alphas (Continued)

Panel C. Sorts on value beta

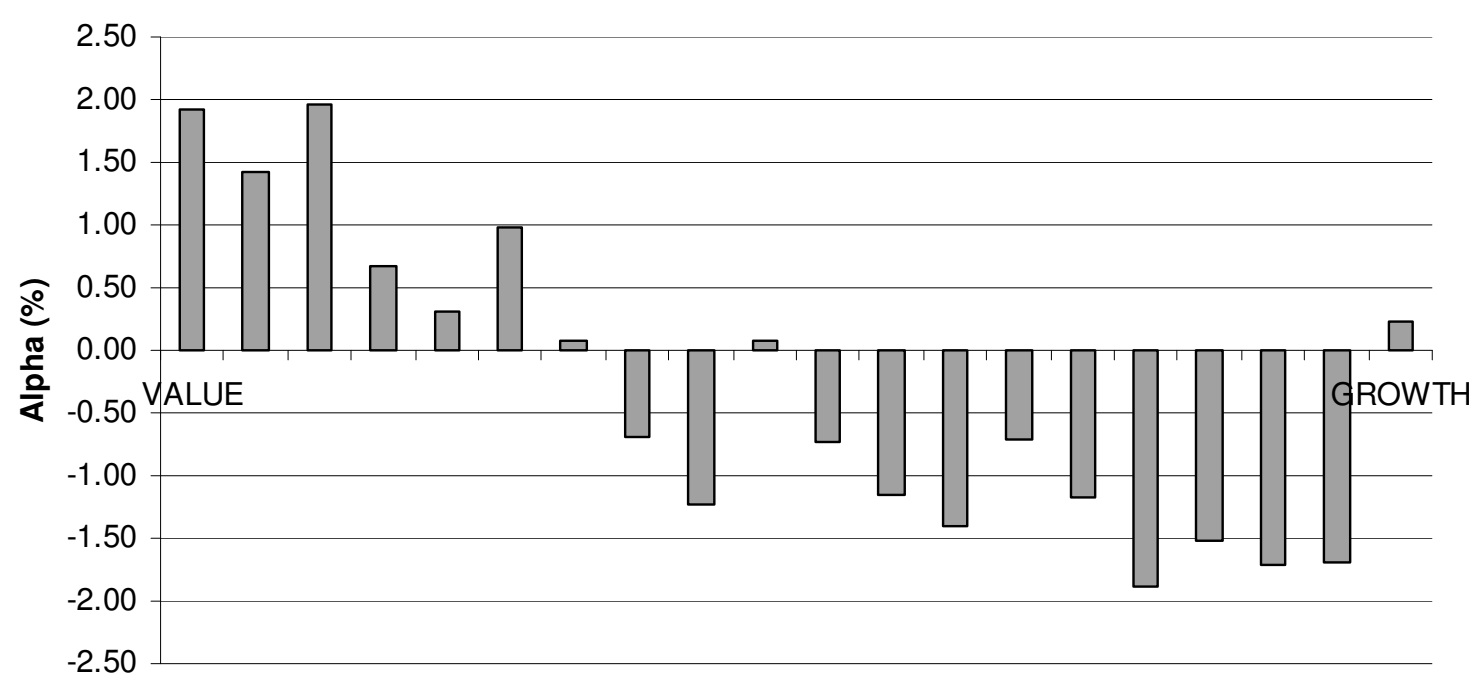

Panel D. Sorts on past return

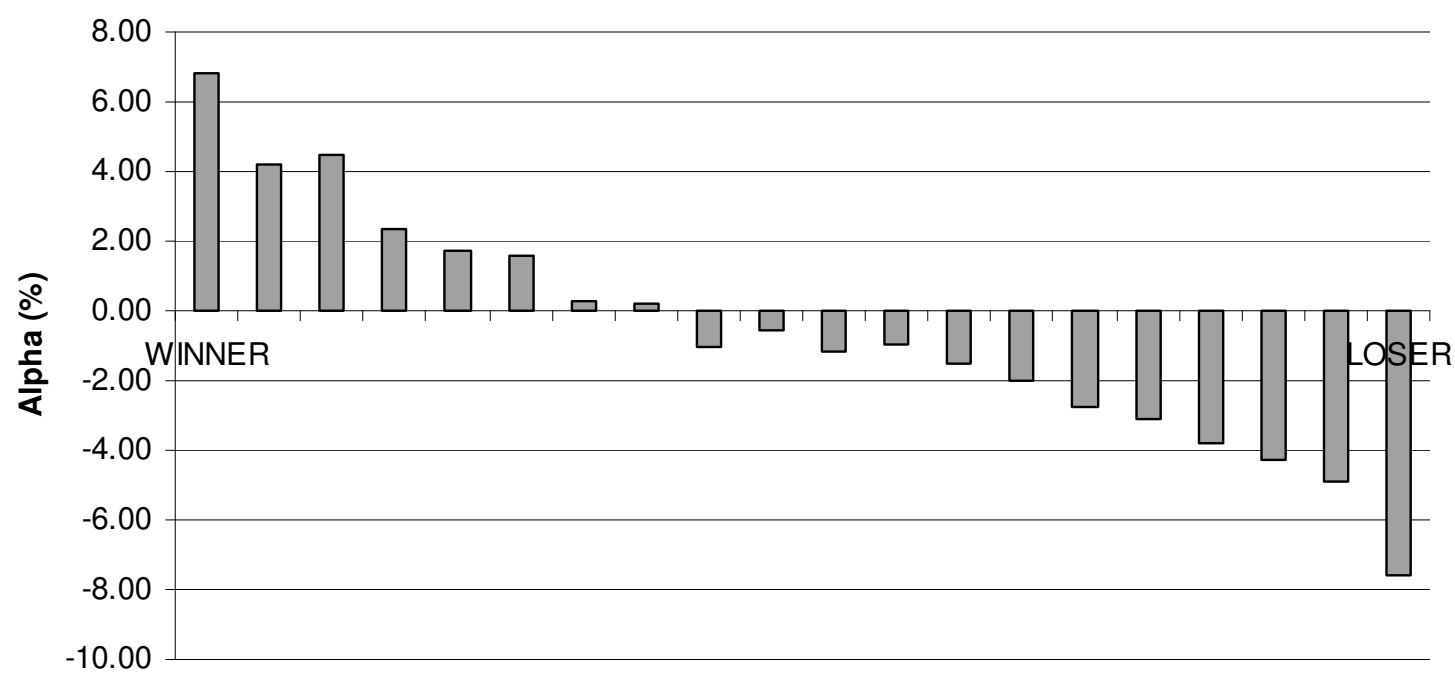

We obtain our data on returns of mutual funds from the 2003 CRSP Mutual Fund Survivor-Bias-Free Database. Our sample comprises 7,852 U.S. equity funds over the period 1963-2003. We sort funds into 20 quantile portfolios based on the market beta (Panel A), size beta (Panel B), value beta (Panel C), and past returns of their stock holdings (Panel D). For the resulting style portfolios, we run single-factor CAPM regressions. The graph panels list the style portfolios' alphas. All values are annualized. 